\title{
Calculating the coverage of saturated and sub-saturated layers of carbon monoxide adsorbed onto platinum
}

\author{
G. J Offer, and A.R. Kucernak ${ }^{\dagger}$ \\ Department of Chemistry \\ Imperial College London \\ London SW7 2AZ, United Kingdom
}

\begin{abstract}
Adsorption and subsequent stripping of $\mathrm{CO}_{\text {ads }}$ from catalyst surfaces is an important process used in the determination of active surface area in a range of electrocatalyst systems. Crucial to this process is a measure of how to relate the stripping charge to the actual amount of $\mathrm{CO}$ which was adsorbed. In this paper a new experimental approach to measure CO coverage is introduced. By utilising an impinging jet (wall-jet) irrigation system with microelectrodes it is possible to operate under conditions of uniform access. This approach is used to accurately determine the saturated $\mathrm{CO}_{\text {ads }}$ adlayer coverages using coulometric methods alone even in the presence of background Faradaic processes. A method for determining sub-saturated $\mathrm{CO}_{\mathrm{ads}}$ adlayer coverages prepared either by partial admission, or partial oxidation of a saturated adlayer is also presented. This approach is used to assess $\mathrm{CO}_{\text {ads }}$ adlayer coverage on platinum. It is shown that at a $\mathrm{CO}$ admission potential of $100 \mathrm{mV}$ failing to take into account the charges associated with $\mathrm{CO}$ adsorption, and only using the charges measured during the $\mathrm{CO}_{\text {ads }}$ oxidation would result in an $34 \%$ underestimate of the $\mathrm{CO}_{\text {ads }}$ coverage. A saturated coverage of $\mathrm{CO}$ on $\mathrm{Pt}$ of 0.68 is found, and these saturated layers are shown to be stable over a period of at least 100 minutes in the presence of low concentrations of oxygen $\left(45 \mathrm{nmol} \mathrm{dm}^{-3}\right)$. The $\mathrm{CO}$ adsorption transient is experimentally determined at $298 \mathrm{~K}$, and a mathematical expression for the CO coverage with time under conditions of defined mass transport is derived. Fitting the experimental data to the theoretical adsorption transient equation yields a value for the $\mathrm{CO}$ adsorption rate constant, $k_{a d}$ of $0.0086 \mathrm{~cm} \mathrm{~s}^{-1}$.
\end{abstract}

Keywords: CO, carbon monoxide, oxidation, adsorption, platinum, electrode, surface, catalyst, fuel cell

\footnotetext{
${ }^{\dagger}$ Corresponding author: a.kucernak@imperial.ac.uk, Phone: +44 20 75945831; Fax: +44 2075945804
} 


\section{Introduction}

Calculation of the absolute $\mathrm{CO}_{\mathrm{ads}}$ coverage on transition metals, for instance Pt, is difficult [1]. The difficulties have been commented on since 1965 when Brummer and Ford [2] sought to clarify some discrepancies in the charges associated with oxidising complete $\mathrm{CO}_{\text {ads }}$ adlayers in the work by Gilman [3], and Warner and Schuldiner [4], by correcting for oxide formation and double layer charging.

Weaver et al. [5] reported the maximum coverage for a saturated $\mathrm{CO}_{\text {ads }}$ adlayer on $\mathrm{Pt}(111)$ in perchloric acid to be $\theta_{\mathrm{CO}, \max }=0.6-0.7$. This was stated to be in contrast to that reported by Feliu et al. [6] for saturated $\mathrm{CO}_{\mathrm{ads}}$ adlayers on $\mathrm{Pt}(111)$ in sulphuric acid with coverages of $\theta_{\mathrm{CO}, \max }=0.9 \pm 0.1$. Although at the same time Feliu et al. also corrected their own results in a paper presenting a novel charge displacement technique [7] which was used in subsequent papers [8, 9]. Weaver et al. [5] conducted an evaluation of the coverages reported in the literature for saturated irreversibly adsorbed $\mathrm{CO}_{\mathrm{ads}}$ adlayers on low-index Pt using both electrochemical and non-electrochemical methods; such as thin-layer IR spectrophotometry (FTIR), scanning tunnelling microscopy (STM), low-energy electron diffraction (LEED) and studies in ultrahigh vacuum (UHV). This led them to consider the maximum coverage to be no greater than 0.75 , and any higher numbers obtained through electrochemical determinations are because not all Faradaic and Non-Faradaic processes have been taken into consideration. Therefore they concluded that in order to estimate reliable coverages it is necessary to provide independent checks using non-coulometric methods, or a more careful widespread consideration of all the factors responsible for the limitations of the existing coulometric methods. Often, the suppression of the hydrogen desorption peaks on $\mathrm{Pt}$ is used to determine $\mathrm{CO}_{\mathrm{ads}}$ coverage, where maximum suppression corresponds to maximum coverage, however this cannot be used to determine absolute saturation coverage and only gives a relative coverage. In addition it does not take into account any double-layer, anion adsorption or other charging effects. In 1998 Weaver and Feliu et al. [10] wrote a paper reviewing the double-layer charge-correction method which is still considered as the authoritative text on this subject to this date. This work presented in this paper builds on that technique and discusses its application to the calculation of sub-saturated layers of carbon monoxide on platinum.

In summary, it is possible to calculate the charge associated exclusively with $\mathrm{CO}_{\text {ads }}$ oxidation provided all the charges associated with both admitting and oxidising a $\mathrm{CO}_{\text {ads }}$ adlayer are measured [1, $10,11]$. Despite this, it is still possible to see $\mathrm{CO}_{\mathrm{ads}}$ coverages calculated using the $\mathrm{CO}_{\text {ads }}$ oxidation peak alone [12]. In addition, background Faradaic processes often occur which can cause difficulty in accurate calculation. Calculating partial adlayer coverage is often done by comparing the stripping charge to that for a saturated adlayer [13]. 
As we move from model electrodes (i.e. single crystal) towards real electrocatalysts (nanoparticles), there is a significant change in surface morphology. The number of step and defect sites increases dramatically, and thus there is a much greater heterogeneity in the type of surface site. Although single crystal electrodes are the easiest to characterise, we were concerned with establishing reliable techniques for real electrocatalysts, and in particular for fuel cell catalysts [14] and as such have focussed on polycrystalline electrodes.

In this work we develop an approach to determine accurate $\mathrm{CO}_{\mathrm{ads}}$ adlayer coverages using coulometric methods alone with the aim of developing accurate approaches for use with highly dispersed electrocatalysts. We apply this approach to the determination of $\mathrm{CO}_{\mathrm{ads}}$ coverage on platinum. This approach allows the accurate determination of the saturated $\mathrm{CO}_{\text {ads }}$ adlayer coverage even in the presence of background Faradaic processes. We also show how this approach may be used to produce and determine sub-monolayer coverages of $\mathrm{CO}_{\text {ads }}$.

\section{Experimental}

$\mathrm{H}_{2} \mathrm{SO}_{4}$ (Merck, Aristar), nitrogen (Air Products, BIP grade), hydrogen (AIR Products, UltraPure grade) and carbon monoxide (BOC, standard grade) were used as obtained. All solutions were $0.5 \mathrm{~mol}$ $\mathrm{dm}^{-3} \mathrm{H}_{2} \mathrm{SO}_{4}$ and were prepared with Milli-Q water $(18.2 \mathrm{M} \Omega \mathrm{cm}$ ). All the experiments were conducted at a temperature of $25^{\circ} \mathrm{C}\left( \pm 1^{\circ} \mathrm{C}\right)$. All current densities reported are in terms of the electrochemical surface area of the electrode, calculated from the hydrogen adsorption and desorption charge $\left(Q_{H_{\text {upd,adsorption }}}, Q_{H_{\text {upd,desorpion }}}\right)$, and the number of surface platinum atoms per unit area $\left(N_{0}\right)$ multiplied by Faraday's constant - a charge density of $210 \mu \mathrm{Ccm}^{-2}$ for a monolayer of adsorbed hydrogen on platinum [15]:

Equation 1. $A_{\text {electrochenical }}=\frac{\left(\frac{Q_{H_{\text {upd,desorprion }}}-Q_{H_{\text {upd,adsorption }}}}{2}\right)}{N_{0} F}$

\subsection{The impinging jet}

An impinging jet flow cell configuration relying on one out of several different gravity-fed electrolytes being selected by a motorised switch was used to irrigate the working electrode, Figure 1. This configuration is similar to that previously described $[16,17]$. The impinging jet configuration enables electrochemical experiments to be carried out in very clean and reproducible conditions. By nature of the configuration the electrode is irrigated with fresh electrolyte continuously. The electrolyte bathing the electrode may be quickly changed whilst maintaining full electrochemical control of the system. It is thus ideally suited to study electrochemical surface modification and the resultant effects on reactions or processes [17]. 


\subsection{Cleanliness}

The cleanliness of the system is extremely important when investigating the oxidation of $\mathrm{CO}_{\mathrm{ads}}$ on Pt. Some workers have considered that $\mathrm{CO}$ is such a strong adsorbate that it will displace any potential contaminants [11], however this has been shown to be not completely true, with a competitive adsorption between $\mathrm{CO}_{\mathrm{ads}}$ and $\mathrm{H}_{\text {ads }}$ existing at potentials within the hydrogen region [18-24]. Cleanliness is crucial in observing this phenomenon. Indeed one of the earliest papers to witness the early onset of $\mathrm{CO}_{\mathrm{ads}}$ oxidation and assign it to the formation of free sites in the $\mathrm{CO}_{\text {ads }}$ adlayer formed at admission potentials within the hydrogen region, may well have witnessed the early onset due to the extremely high cleanliness levels needed for their single crystal preparation [25].

In this paper the criteria of cleanliness for Pt electrode surfaces as described by Conway et al in 1973 was adopted [26]. The following procedures and precautions were taken to ensure cleanliness. All glassware, reservoirs, pipes, connectors, valves and internal cell components were soaked in-situ in acidified permanganate solution overnight, rinsed with acidified peroxide solution and then rinsed at least 7 times with water prior to use. No contact with any internal components was allowed once the cleaning procedure was started, and any accidental contact required the procedure to be restarted. $6 \mathrm{~N}$ rated regulators, steel pipes, and PTFE lined steel hoses were used for the gas lines and the cell and reservoirs were always maintained at positive pressure. Electrolyte flow was maintained continuously throughout operation, and all components in contact with electrolyte were fabricated from glass or PTFE.

It was possible to achieve consistent levels of cleanliness characterised by less than $5 \%$ loss of the hydrogen desorption charge after potentiodynamic sweeping between $0.05 \mathrm{~V}$ to $0.40 \mathrm{~V}$ over a period of 1 hour, and it was possible to maintain the cleanliness of the system at such levels continuously for over 2 weeks.

\subsubsection{The importance of suppressing background faradaic processes}

As many of the adsorption processes may take 10's of seconds to complete, and the currents associated with those processes due to anion displacement and double layer restructuring are very small, it is important that any background faradaic processes are suppressed. As great care was taken to remove any contaminants, it was found that the main issue was associated with very small levels of adventitious oxygen despite the cell being under a positive pressure of nitrogen and all solutions having been degassed for at least 1 hour prior to investigation.

The amount of oxygen in the system was estimated by comparing the diffusion limiting ORR (oxygen reduction reaction) current to the diffusion limiting hor (hydrogen oxidation reaction) current in a $\mathrm{H}_{2}$-saturated solution for the same electrode under the same conditions and assuming that the oxygen was being reduced under diffusion limiting conditions. 
Equation 2. $c_{\mathrm{O}_{2}}=-c_{\mathrm{H}_{2}} \times \frac{i_{\text {orr }} n_{\text {hor }}}{i_{\text {hor }} n_{\text {orr }}} \times \frac{D_{\mathrm{H}_{2}}}{D_{\mathrm{O}_{2}}}$

An average diffusion limited ORR current from 5 experiments of $1.6 \mathrm{nA}\left(4 \mu \mathrm{Acm}^{-2}\right)$ was achievable after completely oxidising a monolayer of $\mathrm{CO}_{\text {ads }}$ at $700 \mathrm{mV}$ and returning to $100 \mathrm{mV}$ for $120 \mathrm{~s}$ using the $125 \mu \mathrm{m}$ electrode. A diffusion limited HOR current of $26.8 \mu \mathrm{A}\left(70 \mathrm{mAcm}^{-2}\right)$ was achievable using the same electrode. Utilising literature values for hydrogen concentration and diffusion coefficient of $7.2 \times 10^{-4} \mathrm{~mol} \mathrm{dm}^{-3}$ [27] and $3.8 \times 10^{-5} \mathrm{~cm}^{2} \mathrm{~s}^{-1}$ [28], respectively and a diffusion coefficient for oxygen of $1.8 \times 10^{-5} \mathrm{~cm}^{2} \mathrm{~s}^{-1}$ [29], an oxygen concentration of $45 \times 10^{-9} \mathrm{~mol} \mathrm{dm}^{-3}$ is calculated using Equation 2 .

The nitrogen used in the experiments was AIR Products BIP $\mathrm{N}_{2}$ which is certified to contain less than $10 \mathrm{ppb}$ of $\mathrm{O}_{2}$. Therefore it is assumed that some oxygen must be entering the cell from elsewhere. In comparison to the concentration for saturated oxygen of $2.6 \times 10^{-4} \mathrm{~mol} \mathrm{dm}^{-3}$ reported [30] the value here is roughly $0.017 \%$ of the saturated value. The most likely candidate for $\mathrm{O}_{2}$ entering the solution lines is through the PTFE parts of the rotary valve, as PTFE has a high $\mathrm{O}_{2}$ permeability.

Even this very small concentration of oxygen can have a profound effect upon calculating $\mathrm{CO}_{\text {ads }}$ coverages, and unless it is taken into account can lead to very significant errors as demonstrated below.

\subsubsection{Electrode manufacturing}

Whilst using bead electrodes of the type described by Bergelin et al. [17] we observed behaviour consistent with the presence of small amounts of $\mathrm{CO}$ in the second scan of the cyclic voltammograms after oxidation of $\mathrm{CO}_{\text {ads }}$ adlayers in the presence of $\mathrm{N}_{2}$-saturated solution. This suggested that such electrodes appear to maintain a reservoir of stagnant solution at the boundaries of the meniscus that could harbour contaminants, in particular dissolved $\mathrm{CO}$ that had been introduced during the admission phase. The contaminants could then adsorb onto the area of the electrode exposed to the stagnant solution even after electrochemical cleaning. Bead electrodes were therefore replaced with microelectrodes produced by sealing Pt wire into soda glass tubes. In addition this also made it possible to achieve uniform access of reactants to the electrode as described in section 2.2.3.

Production of electrodes used an improved method, broadly based on that described by Wipf et al. [31]. Briefly, custom made high purity soda glass tubes $(3.0 \mathrm{~mm}$ o.d. $1.0 \mathrm{~mm}$ i.d. $100 \mathrm{~mm}$ length, Plowden \& Thompson Ltd, UK) were cleaned using the permanganate procedure described above, dried, and then one end was sealed in a Bunsen flame. $125 \mu \mathrm{m}$ or $25 \mu \mathrm{m}$ diameter Pt wire $(99.99+\%$ Advent Research Materials Ltd, UK) was cleaned by soaking in acidified peroxide solution overnight then electrochemically cleaned in sulphuric acid solution by repeatedly scanning between $0 \mathrm{~V}$ and $1.2 \mathrm{~V}$, stopping at OV. The dried Pt wire was then inserted into the glass tube, tapped down and then sealed into the glass. Sealing was achieved by attaching the glass tube to a vacuum at its open end and heating in a resistance wire coil, drawing the coil up the tube to soften the glass and cause it to contract 
around the platinum wire. After cooling, the protruding Pt wire was a connected to a small copper coil soldered to a large copper wire using a small amount of Indium (99.99+\% Advent Research Materials Ltd, UK). The electrode was then polished using aluminium oxide polishing paper (Agar Scientific Ltd, $\mathrm{UK})$ of $30 \mu \mathrm{m}, 9 \mu \mathrm{m}, 3 \mu \mathrm{m}, 1 \mu \mathrm{m}, 0.3 \mu \mathrm{m}$ grade sequentially, to expose the Pt disc. Cleaning of the glass tube and platinum wire are crucial in obtaining a good seal, as was obtaining a good vacuum before any heat was applied.

Electrodes were characterised both visually and electrochemically (double layer and COoxidation) and rejected if they did not pass any test.

Visual inspection was performed after electrochemical measurements and poor electrodes demonstrated crevassing and destruction of the interface between the Pt and glass.

Electrochemical inspections were performed in $0.5 \mathrm{~mol} \mathrm{dm}{ }^{-3} \mathrm{H}_{2} \mathrm{SO}_{4}$. Good electrodes should show no change in the size of the double layer capacitance region after 24 hours soaking in the above electrolyte, indicating minimal creep of solution between the platinum and glass interface. The cyclic voltammogram for the oxidation of a saturated $\mathrm{CO}_{\mathrm{ads}}$ adlayer; admitted at $450 \mathrm{mV}$, in the absence of dissolved CO should give rise to a sharp single peak between $600 \mathrm{mV}$ and $800 \mathrm{mV}$ (dependent upon scan rate). The cyclic voltammogram taken immediately after the $\mathrm{CO}_{\text {ads }}$ oxidation sweep should be identical to that taken in $\mathrm{CO}$-free solution immediately before $\mathrm{CO}$ admission and show no behaviour associated with $\mathrm{CO}_{\mathrm{ads}}$ oxidation.

Unsatisfactory electrodes also typically showed more than one $\mathrm{CO}_{\mathrm{ads}}$ oxidation peak. It is assumed that during the admission phase some $\mathrm{CO}$ diffuses into the stagnant zone within the crevasse formed between the Pt and glass of unsatisfactory electrodes. This reservoir of $\mathrm{CO}$ then complicates the electrochemistry and gives rise to extra peaks during the initial oxidation or during the subsequent voltammetric scan.

\subsubsection{Achieving uniform access using wall-jet electrodes}

Uniform access is important in electrochemical experiments where the diffusion of either reactants to the electrode or products from the electrode can contribute to the overall reaction rate. Uniform access is also important when preparing an adlayer of adsorbed species.

The main issue with the impinging jet approach is associated with the non-uniform access of walljet type cell configurations [32]. This occurs because of differences in flow velocities of the fluid as a function of distance from the centre of the jet, and the formation of a central region within which the fluid is virtually stagnant. The net result is that the boundary layer thickness varies as a function of position across the jet. If the electrode is placed axially immediately above the jet, then the effects of non uniform access are exasperated as the boundary layer thickness increases at the central symmetry axis. 
In order to assess the extent of non-uniform access, a movable stage was constructed allowing translation of the electrode with a $1 \mu \mathrm{m}$ resolution across the jet. When the electrode is symmetrically placed above the centre of the jet, the limiting current is at a minimum, and the current rapidly rises to a broad maximum before falling away at distances greater than the radius of the impinging jet, Figure 2 . It can be seen in Figure 2 that the maximum in the limiting current curve is rather broad.

Also shown in Figure 2 is the variation of boundary layer thickness with displacement from the centre of the jet, calculated from Fick's first law [33] assuming linear diffusion to the electrode, a concentration of zero at the electrode interface and values of the diffusion coefficient and concentration of hydrogen of $3.8 \times 10^{-5} \mathrm{~cm}^{2} \mathrm{~s}^{-1}$ [28] and $7.2 \times 10^{-4} \mathrm{~mol} \mathrm{dm}^{-3}$ [27] respectively. This curve shows a minimum at the point of maximum current and is quite broad. Indeed, if a $125 \mu \mathrm{m}$ diameter electrode is situated at the centre of this minimum, then the boundary layer thickness varies by no more than $1 \%$ from its mean value across the entire face of the electrode. Hence, by positioning the electrode at this physical point, we are confident that the system is operating under acceptable uniform access - a situation which would not exist with electrodes which were significantly larger.

\section{Results and discussion}

In the following sections the measurement of the charges associated with $\mathrm{CO}$ adsorption and oxidation under different conditions are discussed. During $\mathrm{CO}$ adsorption and oxidation the nature of the interface may change quite considerably, as described in the introduction, and this may give rise to a number of electrochemical currents, not all of which are due to faradaic processes. Initially, the simplest case where a saturated adlayer is prepared and then oxidised is considered, taking into account each of the different processes which may occur. In the second section this approach is taken one step further to consider the case where only a partial adlayer is formed and oxidised off of the surface.

\subsection{Saturated adlayers}

$\mathrm{CO}_{\text {ads }}$ coverages are all calculated relative to the hydrogen desorption and adsorption coverages using the following equation.

Equation 3. $\quad \theta_{C O}=\frac{Q_{C O_{\text {oxidation }}}}{Q_{H_{\text {desorption }}}-Q_{H_{\text {adsorption }}}}$

$Q_{C O_{\text {oxidation }}}$ is the $\mathrm{CO}$ oxidation charge corrected for all other Faradaic and non faradaic processes. A typical CO experiment involves (a) Admission: holding the electrode at an admission potential, and dosing the surface with CO; (b) Purging: removing any free CO from solution; (c) Stripping: scanning the potential up until all of the $\mathrm{CO}_{\text {ads }}$ is oxidised; and (d) either a reverse scan; stepping the potential back down to the admission potential, or a background scan; repeating steps a to $\mathrm{c}$ in the absence of $\mathrm{CO}$. 
After this complete cycle, the surface is either in the same state as it started, or the same state as the background scan, and the only difference should be that some $\mathrm{CO}$ has been oxidised to $\mathrm{CO}_{2}$, Figure 3 .

By measuring and summing the charges associated with each of these processes, it is possible to determine the charge associated with just the $\mathrm{CO}$ oxidation process. In the past, this process has been somewhat tedious because of the long delays required to remove all of the $\mathrm{CO}$ from solution during step (b). During the admission process, CO adsorbs on the surface, and there may be partial charge transfer, however, for $\mathrm{CO}$ admission the electrosorption valency is often assumed to be zero [7], which is the same assumption made here. At the same time, the CO can displace hydrogen (if the adsorption is performed in the hydrogen region), anions (if present), water or any other species adsorbed on the surface. Displacing the adsorbed hydrogen will result in a positive charge. As many anions are partially discharged on adsorption (i.e. they have a non-zero electrosorption valency), their displacement will result in a negative charge for adsorption potentials less than the potential of zero total charge.

Equation 4. $\mathrm{H}_{a d s}+\mathrm{CO}_{b u l k} \rightarrow \mathrm{H}_{a q}^{+}+\mathrm{CO}_{a d s}+e^{-}$

Equation 5. Anion ${ }_{a d s}^{(1-\gamma)}+\gamma e^{-}+\mathrm{CO}_{b u l k} \rightarrow$ Anion $_{a q}^{-}+\mathrm{CO}_{a d s}$

Finally there is also charge associated with the change in double layer structure resulting in a decreased capacitance for the electrode.

Equation 6. $Q_{\text {Admission }}=Q_{C O_{a d s}}+(1-x) Q_{H_{\text {desorption }}}-Q_{\text {DoubleLayd }}-Q_{\text {AnionAds }}$

Where $Q_{C O_{a d s}}$ is the charge associated with any charge transfer during the adsorption of the CO. $(1-x) Q_{H_{\text {desorpion }}}$ is the charge associated with the oxidation of adsorbed hydrogen which has been displaced by the $\mathrm{CO}_{\mathrm{ads}}$. $\mathrm{x}$ ' is the proportion of the adsorbed hydrogen which is not displaced by $\mathrm{CO}_{\mathrm{ads}}$. $Q_{\text {Doublelaye }}$ is the charge associated with the change in capacitance of the electrode due to $\mathrm{CO}$ adsorption. $Q_{\text {AnionAds }}$ is the charge association with the adsorption of anions onto the surface (in this case we expect anion desorption, i.e. $Q_{\text {AnionAds }}$ is negative ).

It is assumed that during the purging process, neither the potential nor the species adsorbed on the electrode change. This may not be true, as either some $\mathrm{CO}_{\mathrm{ads}}$ oxidation or $\mathrm{CO}_{\mathrm{ads}}$ desorption may take place, or a relaxation in the compression structure of the $\mathrm{CO}_{\mathrm{ads}}$ adlayer may take place as the equilibrium between $\mathrm{CO}_{\mathrm{ads}}$ and $\mathrm{CO}_{\text {bulk }}$ is changed [18], this is discussed more fully below. For the purposes of calculating coverage it is assumed that no appreciable change in the adlayer will happen over the timescale of the purging, which is nonetheless quite fast for these experiments at about 10 s and occurs immediately after the admission process. Experimentally this is seen, and the current measured 
is effectively zero over this period. The nature of the experimental procedure means that $Q_{\text {purging }}$ is effectively part of the admission process and is therefore can be ignored as a separate step.

During the stripping process $\mathrm{CO}_{\mathrm{ads}}$ is oxidised and any remaining adsorbed hydrogen is also oxidised. The double layer and adsorbed anions are re-established, and there is growth of oxide. Because of the change in potential, there is some modification to the anion coverage, and the total charge associated with the double layer is also modified ( $\Delta Q_{\text {AnionAds }}, \Delta Q_{\text {DoubleLayd }}$ respectively).

\section{Equation 7.}

$$
Q_{\text {Stripping }}=Q_{C O_{\text {oxidation }}}-Q_{C O_{\text {ads }}}+(x) Q_{H_{\text {desorpion }}}+Q_{\text {DoubleLayr }}
$$

$$
+Q_{\text {OxideGrowh }}+Q_{\text {AnionAds }}+\Delta Q_{\text {DoubleLayr }}+\Delta Q_{\text {AnionAds }}
$$

During the reverse step, the oxide is reduced, hydrogen is adsorbed, and charge is consumed in anion desorption and changes to the double layer structure.

Equation 8. $Q_{\text {ReverseStep }}=-Q_{H_{\text {desorpion }}}-Q_{\text {OxideGrowh }}-\Delta Q_{\text {DoubleLayd }}-\Delta Q_{\text {AnionAds }}$

Or if a background correction is used:

Equation 9. $Q_{\text {Background }}=Q_{H_{\text {desorpion }}}+Q_{\text {OxideGrowh }}+\Delta Q_{\text {DoubleLayd }}+\Delta Q_{\text {AnionAds }}$

Although the background charge is actually made up of a number of background transients $Q_{\text {BackgroundAdmission }}$ and $Q_{\text {BackgroundStripping }}$ which added together will give $Q_{\text {Background }}$. In practice it is usually necessary to correct each step individually, subtracting $Q_{\text {BackgroundAdmission }}$ from $Q_{\text {Admission }}$ and $Q_{\text {BackgroundStripping }}$ from $Q_{\text {Stripping }}$. This must be done exceedingly carefully, as discussed below, in particular because some Faradaic processes such as the ORR will occur during the background, but not after CO has been adsorbed.

Charges calculated using Equation 9 or Equation 8 should theoretically be identical but of opposite sign, as in both cases the surface should be entirely free of $\mathrm{CO}_{\text {ads }}$ and the only difference is in the direction of the potential sweep or step. However, some differences in the amount of oxide growth that has occurred may conceivably occur if the surface examined after the oxidation of $\mathrm{CO}_{\text {ads }}$ has not had time to equilibrate, and therefore Equation 8 should be more reliable than Equation 9 as this will be independent of whether the system has equilibrated or not. In practice this is also not always the case as other factors complicate the situation, in particular the presence of small amounts of oxygen, which necessitate the use of background transients and Equation 9. This is discussed fully below.

The sum of these four processes represent a complete cycle, with the net difference in charge attributable solely to $\mathrm{CO}$ oxidation, therefore the charge attributed solely to the oxidation of $\mathrm{CO}$ can be calculated using either of the following equations. 
Equation 10. $Q_{C_{\text {oxidation }}}=Q_{\text {Admission }}+Q_{\text {Stripping }}+Q_{\text {ReverseSte } \mathrm{p}}$

Equation 11. $Q_{C_{O_{\text {oxidation }}}}=Q_{\text {Admission }}+Q_{\text {Stripping }}-Q_{\text {BackgroundAdmission }}-Q_{\text {BackgroundStripping }}$

An exhaustive analysis of how this is done experimentally is described below.

The typical approach used within the literature [34] to measure CO oxidation charge is to subtract $Q_{\text {ReverseScan }}$ (or occasionally $Q_{\text {BackgroundStripping }}$ ) from $Q_{\text {Stripping }}$ to produce an indicative CO oxidation charge,

Equation 12. $Q_{\text {CO }_{\text {oxidation }}^{\prime}}=Q_{\text {Stripping }}+Q_{\text {ReverseStep }}$

or,

Equation 13. $Q_{C O_{\text {oxidation }}^{\prime}}^{\prime}=Q_{\text {Stripping }}-Q_{\text {Background }}$

The relative error associated with this simplification may be estimated as

Equation 14. Error $\left(C O_{\text {oxidation }}\right)=\frac{Q_{C O_{\text {oxidation }}}-Q_{C O_{\text {oxidation }}}^{\prime}}{Q_{C O_{\text {oxidation }}}}=\frac{Q_{\text {Admission }}+Q_{\text {Purging }}}{Q_{\text {Admission }}+Q_{\text {Purging }}+Q_{\text {Stripping }}+Q_{\text {ReverseStep }}}$

It is useful to assess this error in terms of describing the absolute charge associated with the oxidation of $\mathrm{CO}_{\mathrm{ads}}$.

\subsubsection{CO admission phase}

The chronoamperometric transients in Figure 4(a) show the effect of switching from Reservoir 2 $\left(\mathrm{N}_{2}\right.$ saturated CO-free $\mathrm{H}_{2} \mathrm{SO}_{4}$ ) to Reservoir 1 ( $\mathrm{CO}$ saturated $\mathrm{H}_{2} \mathrm{SO}_{4}$ ) about 20 s after the transient starts. For comparison, the case when both reservoirs $1 \& 2$ are filled with $\mathrm{N}_{2}$ saturated $\mathrm{CO}$-free $\mathrm{H}_{2} \mathrm{SO}_{4}$ is also shown (grey transient). In this latter case a transient is seen which takes almost 300 s to stabilise. This long-time cathodic current, in absolute terms only $0.66 \mathrm{nA}\left(1.7 \mu \mathrm{Acm}^{-2}\right)$, is associated with the presence of a small amount of residual oxygen in the electrolyte as described above. The initial decay is associated with residual oxygen diffusing through the ptfe valve body. The flux of oxygen into the electrolyte decreases with time as the reservoir of oxygen dissolved in the ptfe is consumed. It must be stressed that the amount of oxygen is very small, $\sim 45 \times 10^{-9} \mathrm{~mol} \mathrm{dm}^{-3}$, and it is an indication of the sensitivity of these experiments that it can be detected.

When the second electrolyte contains CO (Figure 4(a) black line), the transient is initially the same until about $35 \mathrm{~s}$ when the $\mathrm{CO}$ containing electrolyte starts bathing the electrode. As soon as the $\mathrm{CO}$ containing solution bathes the electrode there is an immediate anodic peak due to the oxidation of adsorbed hydrogen as it is displaced by the adsorbed $\mathrm{CO}$, Equation 4 . This peak decays very quickly and is replaced by a much slower cathodic transient as anion desorption becomes significant, Equation 
5. Once a $\mathrm{CO}_{\text {ads }}$ monolayer has been formed the $O R R$ current is effectively suppressed as the $C O_{\text {ads }}$ monolayer blocks the adsorption of $\mathrm{O}_{2}$ and hence stops the $O R R$ reaction.

In order to calculate the charge due to the admission of $\mathrm{CO}$ alone it is necessary to correct for the effect of the ORR. This is complicated by the fact that the ORR is suppressed during CO adsorption. A subtraction of the transient when no $\mathrm{CO}$ is admitted (grey line, Figure 4 (a)) from the transient when CO is admitted is shown in Figure 4(b). It is clear from this transient that it is possible to remove any charge contributions from processes occurring before the $\mathrm{CO}$ admission takes place. However, at long time this transient does not decay to zero, but shows a positive current because of the suppression of the ORR on the CO covered surface.

To overcome this effect we construct a non-constant baseline for the integration as shown in Figure 4(b). This baseline is an extrapolation of the transient before CO admission takes place and at long time after $\mathrm{CO}$ admission has taken place, with a transition between the two baselines at the exact moment of the peak current. This is based upon the assumption that the ORR current will decrease linearly with increasing $\mathrm{CO}_{\text {ads }}$ coverage, and that the $\mathrm{CO}$ adsorption/displacement peak is symmetrical.

\subsection{2 $\mathrm{CO}_{\mathrm{ads}}$ oxidation phase}

Figure 5(a) shows the current measured during the $\mathrm{CO}_{\text {ads }}$ oxidation phase. There is an initial large spike which has been attributed to the removal of upd hydrogen and double layer charging which is larger for the control surface which has no $\mathrm{CO}_{\text {ads }}$ present, and this decays away rapidly. For the surface with $\mathrm{CO}_{\mathrm{ads}}$ present there is significant oxidative current after approximately $1 \mathrm{~s}$, with a pronounced asymmetric peak, peaking at approximately $2.5 \mathrm{~s}$ and with the current decaying away to that seen for the control after approximately 20 s.

In order to correctly determine the charge associated with oxidising the $\mathrm{CO}_{\text {ads }}$ on the surface it is necessary to subtract the control transient from the transient for which $\mathrm{CO}_{\text {ads }}$ is present. This is shown in Figure 5(b). Note that initially there is a negative current. This is associated with the removal of the upd hydrogen from the control surface, for which the charge is far greater than the removal of the remaining upd hydrogen on the surface covered with $\mathrm{CO}_{\mathrm{ads}}$. After this initial negative current the current becomes positive as the current associated with $\mathrm{CO}_{\mathrm{ads}}$ oxidation starts to increase rapidly, and the current then decays away to zero as the surface becomes identical to that of the control. All of the charges here must be included, as the initial negative current due to removal of upd hydrogen from the control was instead passed during the $\mathrm{CO}$ admission process and therefore must be taken into account here.

The integration of the charge passed throughout the $\mathrm{CO}_{\text {ads }}$ oxidation process minus the control is shown in Figure 5(c).

The maximum in charge is reached after approximately $30 \mathrm{~s}$, the integrated charge then starts to decay away, although the rate of decay decreases over time. The cause of this is unknown, but it is 
possible that this is again caused by the $O R R$, although the magnitude of the current is far less. However, it is possible to reduce the effect of the discrepancy by taking the maximum charge passed.

The total charge passed throughout this experiment without correcting for the unknown decay was $66.4 \mathrm{nC}$, and including the corrections was $72.7 \mathrm{nC}$. The error without corrections is $-8.6 \%$, equivalent to an underestimation of the $\mathrm{CO}_{\text {ads }}$ coverage by 0.038 , or $5.7 \%$.

\subsubsection{Returning to the admission potential}

It is expected that the chronoamperometric transients for returning to the admission potential for both the background and the oxidation experiments should be identical, as the surfaces should now be in the same state.

This is broadly the case; the difference in charge passed between the $\mathrm{CO}_{\text {ads }}$ oxidation experiment and the background shown was only $0.77 \mathrm{nC}$, which is equivalent to a $\mathrm{CO}_{\text {ads }}$ coverage of 0.0039 , or $0.67 \%$ of the saturated $\mathrm{CO}_{\mathrm{ads}}$ adlayer. Therefore, we assume that the difference between these two charges is experimental error and it is not necessary to include this charge in the coverage calculations.

\subsubsection{Coverage calculations}

The $\mathrm{CO}_{\mathrm{ads}}$ coverages for five independent experiments with independent background experiments, calculated using Equation 10 are shown in Table 1.

A standard deviation of $1.17 \%$ from 5 experiments was considered to be acceptable, and the value of 0.68 is in agreement with similar experiments in the literature for $\mathrm{Pt}(111)$ electrodes, for which the maximum coverage in $\mathrm{CO}$ free $0.1 \mathrm{~mol} \mathrm{dm}^{-3} \mathrm{H}_{2} \mathrm{SO}_{4}$ was shown to be 0.68 [18]. If the coverage had been calculated only from the stripping charge with a background correction, then the coverage would have been calculated as 0.444 , an underestimation of $34 \%$ as calculated by Equation 14 . The error is associated with the extra charge associated with anion adsorption, and so is expected to be potential dependent. It is expected that the error would reduce to zero if the $\mathrm{CO}$ adsorption were done at the potential of zero total charge.

\subsection{Sub-saturated adlayers - Partial Admission}

There are two approaches to produce sub-saturated $\mathrm{CO}_{\text {ads }}$ adlayers on $\mathrm{Pt}$, the first called partial admission involves exposing the Pt electrode to $\mathrm{CO}$ saturated solution for controlled periods of time below that needed to obtain a saturated adlayer, and the second called partial oxidation involves exposing the Pt electrode to $\mathrm{CO}$ saturated solution until a saturated adlayer is achieved and then partially oxidising the $\mathrm{CO}_{\text {ads }}$ adlayer. In a separate paper we will compare the activity of Pt electrodes towards the hydrogen oxidation reaction with different partial $\mathrm{CO}$ coverages prepared by these two different methods. 
Partial admission is the most difficult approach to prepare sub-saturated $\mathrm{CO}_{\text {ads }}$ adlayer as in normal electrochemical cells it is difficult to control the exposure of the electrode to the $\mathrm{CO}$ saturated electrolyte. Therefore it has only really been studied in the past by Bergelin et al. [17, 35] who used an impinging jet to control the solution flowing over the electrode. As mentioned above we have used the same approach here with some improvements to ensure that there is uniform access of $\mathrm{CO}$ to the electrode surface during the partial admission approach in order to achieve a uniform coverage of $\mathrm{CO}_{\mathrm{ads}}$ across the electrode surface.

Equation 10 can be used for calculating the $\mathrm{CO}_{\text {ads }}$ coverage for saturated and non-saturated $\mathrm{CO}$ adlayers produced by controlling the admission time. In effect, the method for calculating the $\mathrm{CO}_{\mathrm{ads}}$ coverage is exactly the same as described above, the only difference is that the amount of $\mathrm{CO}_{\mathrm{ads}}$ on the surface is less than a full saturated layer as the CO exposure time is shorter than that required to produce such a layer.

Figure 6 displays the coverage of $\mathrm{CO}_{\text {ads }}$ measured as a function of the amount of time that the electrode is exposed to the $\mathrm{CO}$ containing solution. Each point corresponds to a separate adsorption/oxidation experiment. Within about $1 \mathrm{~s}$ the electrode becomes saturated with $\mathrm{CO}_{\text {ads }}$. Further increasing the exposure does not lead to any significant change in $\mathrm{CO}_{\mathrm{ads}}$ coverage. $\mathrm{CO}$ adsorption on the Pt surface requires transport from the bulk ( $\left.\mathrm{CO}_{\text {bulk }}\right)$ to the area immediately adjacent to the electrode $\left(\mathrm{CO}_{\text {surf }}\right)$ and then from there onto the surface $\left(\mathrm{CO}_{\mathrm{ads}}\right)$

Equation 15. $\mathrm{CO}_{\text {bulk }} \stackrel{k_{m t}}{\longrightarrow} \mathrm{CO}_{\text {surf }} \stackrel{k_{\text {ads }}}{\longrightarrow} \mathrm{CO}$ ads

Where $k_{m t}$ represents the mass transport rate constant of the $\mathrm{CO}$ to the immediately adjacent to the surface and $k_{a d s}$ represents the adsorption rate constant of the $\mathrm{CO}$ onto the surface. When $k_{m t}>k_{a d s}$ then the $\mathrm{CO}_{\text {ads }}$ surface concentration ( $\left.c_{\text {surf }}\right)$ is the same as the bulk concentration $\left(c_{\text {bulk }}\right)$ and the rate of adsorption is dominated by $k_{a d s}$. If $k_{m t} \approx k_{a d s}$ then the surface concentration of $\mathrm{CO}_{\text {ads }}$ will be less than the bulk concentration, and it will be necessary to consider both transport steps in order to determine $k_{\text {ads }}$. Finally, when $k_{a d s} \gg k_{m}$, mass transport to the surface is the limiting step, the $\mathrm{CO}_{\mathrm{ads}}$ surface concentration is close to 0 and it is difficult to obtain accurate values of $k_{a d s}$ in any experiment.

As we are under uniform access conditions, and the boundary layer thickness is constant across the electrode, mass transport to the electrode is determined by diffusion through the boundary layer, which is strongly convected on its external boundary. Hence

$$
\text { Equation 16. } k_{m t}=\frac{D_{C O}}{\delta}
$$

Where $\delta$ is the width of the boundary layer, and $D_{C O}$ is the diffusion coefficient of $C O$ in solution. In our experiments the boundary layer thickness is $\sim 4.6 \mu \mathrm{m}$ (Figure 2 , this paper) and utilising a $\mathrm{CO}$ diffusion coefficient $1.46 \times 10^{-5} \mathrm{~cm}^{2} \mathrm{~s}^{-1}$ [36] we obtain a value of $k_{m t}$ of $0.0317 \mathrm{~cm} \mathrm{~s}^{-1}$. Because of the 
controlled geometry of our experiment, and the fact that the boundary layer thickness is uniform, we can determine the flux of reactant to the surface layer using Ficks' first law

$$
\text { Equation 17. } J_{m t}=D_{C O}\left(\frac{c_{\text {bulk }}-c_{\text {surf }}}{\delta}\right)=k_{m t}\left(c_{\text {bulk }}-c_{\text {surf }}\right)
$$

The adsorption of $\mathrm{CO}$ onto platinum (second step in equation 15) in the simplest case may be considered to follow a Langmuir adsorption isotherm in which the $\mathrm{CO}_{\text {ads }}$ adsorbed on the surface is in equilibrium with $\mathrm{CO}$ immediately adjacent to the surface. Hence in the ideal case we also need to include the desorption rate constant for $\mathrm{CO}_{\mathrm{ads}}$ from the surface. However, at the temperature of the experiments performed in this paper $k_{\text {des }}$ is exceedingly small, and $\mathrm{CO}$ adsorption is effectively irreversible (this will be shown later in the paper). Hence we set $k_{\text {des }}=0$.

$$
\text { Equation 18. } P t+C O_{\text {surf }} \underset{k_{\text {des }}}{\stackrel{k_{a d s}}{\rightleftarrows}} \mathrm{Pt}-\mathrm{CO}
$$

The rate of change of $\mathrm{CO}_{\text {ads }}$ surface coverage with time for this situation may be written as

$$
\text { Equation 19. } \frac{\mathrm{d} \theta}{d t}=k_{\text {ads }} c_{\text {surf }}(1-\theta)-k_{\text {des }} \theta=k_{\text {ads }} c_{\text {surf }}(1-\theta)
$$

This ignores any interaction between the adsorbed $\mathrm{CO}_{\text {ads }}$ molecules, which could be modelled using a Frumkin-type correction factor, but which for simplicity we have not done. We can also ascribe a flux of $\mathrm{CO}$ due to this absorption process to the surface

$$
\text { Equation 20. } J_{a d s}=\frac{1}{N_{0, C O}} \frac{\mathrm{d} \theta}{d t}=\frac{k_{a d s}}{N_{0, C O}} c_{\text {surf }}(1-\theta)
$$

Where $N_{o, c o}$ is the number of surface sites on the Pt surface available to adsorb CO (i.e. $\theta_{C O, \text { max }} N_{0}$, where $\theta_{C O, \max }$, the maximum $\mathrm{CO}_{\text {ads }}$ coverage is taken to be 0.68$)$. As the two fluxes must be equal, we can equate Equation 17 and Equation 20 and solve for $c_{\text {sur. }}$ Substituting the resulting expression for $c_{\text {surf }}$ into Equation 19 and rearranging provides an equation for the change in surface coverage of $\mathrm{CO}_{\text {ads }}$ as a function of time under the conditions of our experiment

$$
\text { Equation 21. } \frac{\mathrm{d} \theta}{d t}=\frac{k_{a d s} k_{m t} c_{b u l k}(1-\theta)}{N_{0, C O}\left(k_{a d s} \theta-k_{m t}-k_{a d s}\right)}
$$

The solution of this differential equation is found and incorporates the Lambert W-Function (this function is the inverse function of $\left.f(W)=W e^{W}\right)$,

$$
\text { Equation 22. } \theta[t]=1-\frac{k_{m t}}{k_{a d s}} \mathrm{~W}\left[-\frac{k_{a d s}}{k_{m t}} \operatorname{Exp}\left[\frac{k_{a d s}-\operatorname{const}}{k_{m t}}-\frac{k_{a d s} c_{b u l k} t}{N_{0, C O}}\right]\right]
$$


Where const is the constant of integration. The value of this is determined by solving Equation 19 for const under the boundary condition $\theta_{t=0}=0$. This leads to

Equation 23. $\theta[t]=1-\frac{k_{m t}}{k_{a d s}} \mathrm{~W}\left[\frac{k_{a d s}}{k_{m t}} \operatorname{Exp}\left[\frac{k_{a d s}}{k_{m t}}-\frac{k_{a d s} c_{b u l k} t}{N_{0, C O}}\right]\right]$

This equation was used to fit the data in Figure 6 utilising $k_{a d s}$ as the only fit parameter. The values of the other constants are listed previously and the CO solubility used was $0.96 \times 10^{-6} \mathrm{~mol} \mathrm{~cm}^{3}$ [37]. The nonlinear fit was performed in Mathematica, and resulting best fit value of $k_{\text {ads }}$ is $0.0086 \mathrm{~cm} \mathrm{~s}^{-1}$. This value is within a factor two of the value calculated at $298 \mathrm{~K}$ from the data in Baschuk and Li [38], 0.015 $\mathrm{cm} \mathrm{s}^{-1}$. The error bars shown in Figure 6 reflect the average differences in the coverages calculated using Equation 10 and Equation 11.

From this result we also see that $k_{m t} \approx 4 \times k_{a d s}$ suggesting that these experiments are operating in the intermediate regime where the overall rate of adsorption is controlled by both transport from bulk solution and the actual adsorption process. This confirms the need to take both processes into account within the mathematical derivation.

\subsection{Sub-saturated adlayers - Partial Oxidation}

The partial oxidation process involves the formation of a saturated $\mathrm{CO}_{\text {ads }}$ adlayer followed by the removal of some of that adlayer by oxidation. In order to determine the $\mathrm{CO}_{\text {ads }}$ coverage of the resultant layer, we need to assess not only the saturated $\mathrm{CO}_{\mathrm{ads}}$ coverage, but also assess how much of the $\mathrm{CO}_{\mathrm{ads}}$ has been oxidised during the electrochemical oxidation process.

Figure 7 shows a cartoon of the potential steps applied to the system and the current responses expected when $\mathrm{CO}$ is adsorbed on the electrode during the admission stage (CO oxidation transient) and when no $\mathrm{CO}$ is adsorbed (Control transient). The crucial parameter is $t_{\text {strip }}$ which represents the amount of time that the electrode with a saturated $\mathrm{CO}_{\text {ads }}$ adlayer is oxidised for. During phase (d), other experiments can be performed to probe the nature of the adsorbed layer, although in this paper we have not done so.

Figure 8 shows experimental results for two different values of $t_{\text {strip, }} 0.1$ and $3 \mathrm{~s}$. Reassuringly there is no difference in the transients during the admission phase of the experiment, Figure 8(a). For comparison to these admission transients, Figure $8(\mathrm{~b})$ shows the transient when no $\mathrm{CO}$ is present in the solution during the admission phase. There is a limiting cathodic current plateau when no $\mathrm{CO}$ is adsorbed. This limiting current is much smaller when a saturated $\mathrm{CO}_{\text {ads }}$ adlayer is formed. Figure $8(\mathrm{c})$ shows the transient for the partial oxidation of the $\mathrm{CO}_{\mathrm{ads}}$ adlayer. Both transients overlay each other until $0.1 \mathrm{~s}$ into the transient at which point the potential is switched back to $100 \mathrm{mV}$ for the $t_{\text {strip }}=0.1 \mathrm{~s}$ transients, and a small cathodic reverse transient is seen. That reverse transient is replotted in Figure 
8(d) and overlaid with the equivalent reverse step transient for the $t_{\text {strip }}=3 \mathrm{~s}$ oxidation experiment. It can be seen that the charge associated with the shorter $t_{\text {strip }}$ is smaller, as the surface is still substantially covered with $\mathrm{CO}_{\text {ads}}$, which will reduce the double-layer capacitance and coverage of adsorbed anions. The situation is reversed for the second stripping phase, Figure $8(\mathrm{e})$. In this transient the $t_{\text {strip }}=0.1 \mathrm{~s}$ oxidation experiment shows a larger transient as there is a larger amount of unreacted $\mathrm{CO}_{\text {ads }}$ on the electrode surface. The second reverse steps, Figure 8(f) are identical for the different experiments.

In analysing the charges associated with each of these different transients, we need to modify some of the equations which we previously used for the complete oxidation case. Equation 6 and Equation 8 remain the same, however instead of Equation 7 there are now two oxidation steps and two reverse steps.

Equation 24. $\mathrm{Q}_{\text {stripping }}^{\prime}=(m) Q_{C O_{\text {oxidataion }}}-(m) Q_{C O_{\text {ads }}}+(x) Q_{H_{\text {desorpion }}}+(a) Q_{\text {DoubleLayd }}$ $+($ a $) Q_{\text {AnionAds }}+Q_{\text {OxideGrowh }}^{\prime}+\Delta Q_{\text {DoubleLayr }}^{\prime}+\Delta Q_{\text {AnionAds }}^{\prime}$

Equation 25. $Q_{\text {ReverseStep }}^{\prime}=-(z) Q_{H_{\text {desorphion }}}-Q_{\text {OxideGrowh }}^{\prime}-\Delta Q_{\text {DoubleLaye }}^{\prime}-\Delta Q_{\text {AnionAds }}^{\prime}$

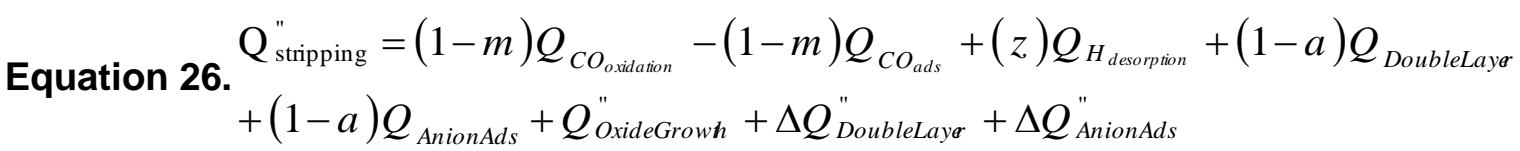

Equation 27. $Q_{\text {ReverseStep }}^{\prime \prime}=-Q_{H_{\text {desorphion }}}-Q_{\text {OxideGrowh }}^{\prime \prime}-\Delta Q_{\text {DoubleLaya }}^{\prime \prime}-\Delta Q_{\text {AnionAds }}^{\prime \prime}$

Where ' $m$ ' represents the proportion of $\mathrm{CO}_{\text {ads }}$ oxidised during the first partial oxidation step; and ' $a$ ' represents the proportion of anion adsorption and double layer charge associated with the loss of the proportion ' $m$ ' of $\mathrm{CO}_{\mathrm{ads}}$ coverage. ' $\mathrm{x}$ ' is the same as before but ' $\mathrm{z}$ ' is an unknown quantity and represents an amount of $\mathrm{H}_{\mathrm{ads}}$ that forms during the first reverse step and is then oxidised during the second (full) oxidation step.

By summing the oxidation step with the reverse step we get the following:

Equation 28.

$$
\begin{aligned}
& \mathrm{Q}_{\text {stripping }}^{\prime}+\mathrm{Q}_{\text {ReverseStep }}^{\prime}=(m) Q_{C O_{\text {oxidaion }}}-(m) Q_{C O_{\text {ads }}}+(a) Q_{\text {DoubleLayar }} \\
& +(a) Q_{\text {AnionAds }}+(x-z) Q_{H_{\text {desorption }}}
\end{aligned}
$$

Equation 29.

$$
\mathrm{Q}_{\text {stripping }}^{\prime \prime}+\mathrm{Q}_{\text {ReverseStep }}^{\prime \prime}=(1-m) Q_{C_{\text {oxidation }}}-(1-m) Q_{C_{\text {ads }}}+(1-a) Q_{\text {DoubleLayar }}
$$

$$
+(1-a) Q_{\text {AnionAds }}-(1-z) Q_{H_{\text {desorption }}}
$$

' $z$ ' is clearly a complicating factor and unfortunately it is not possible to measure ' $z$ ' directly using these experiments, and thus it has to be assumed that the proportion of $\mathrm{H}_{\mathrm{ads}}$ that forms during the first reverse step is proportional to the amount of $\mathrm{CO}_{\text {ads }}$ oxidised during the first partial oxidation step, as shown in Equation 30. The additional difficulty at this stage is that there is only one admission charge 
$Q_{\text {Admission }}$ which contains the following terms; $Q_{C O_{a d s}},(1-x) Q_{H_{\text {desorption }}}, Q_{\text {DoubleLaye }}$, and $Q_{\text {AnionAds }}$. It is therefore necessary to make the further assumption that the electrosorption valencies are independent of coverage, and that no reorganization of the $\mathrm{CO}_{\text {ads }}$ adlayer occurs. Furthermore we assume that changes to the double layer capacitance and coverage of anions vary linearly with $\mathrm{CO}_{\mathrm{ads}}$ coverage. Under these assumptions, the ratio of total charge passed during the two oxidation steps is equal to the ratios of $\mathrm{CO}_{\mathrm{ads}}$ oxidation, hydrogen desorption, double layer reformation and anion adsorption occurring during the oxidation and reverse steps as follows.

Equation 30. $\frac{\mathrm{Q}_{\text {stripping }}^{\prime}+\mathrm{Q}_{\text {ReverseStep }}^{\prime}}{\mathrm{Q}_{\text {stripping }}^{\prime \prime}+\mathrm{Q}_{\text {ReverseStep }}^{\prime \prime}}=\frac{m}{(1-m)}=\frac{a}{(1-a)}=\frac{z}{(1-x)}$

This appears to be the most reasonable approximation possible using our experimental approach. At intermediate coverages there will be some deviation due to adsorbate-adsorbate interactions and/or reorganisation of the $\mathrm{CO}_{\mathrm{ads}}$ adlayer during $\mathrm{CO}_{\mathrm{ads}}$ oxidation, as confirmed by experiments showing that hydrogen adsorption can be completely blocked at coverages below the maximum [39]. However it has not been possible to compensate for these effects as they are relatively poorly understood for this system. This will be explored in a future paper. Therefore the coverage must be calculated as follows.

Equation 31. $Q_{C O_{\text {oxidation }}^{\prime}}^{\prime}=Q_{\text {Stripping }}^{\prime}+Q_{\text {Reverse }}^{\prime}+\left(\frac{Q_{\text {Stripping }+ \text { Reverse }}^{\prime}}{Q_{\text {Stripping }+ \text { Reverse }}^{\prime}+Q_{\text {Stripping }+ \text { Reverse }}^{\prime \prime}}\right) Q_{\text {Admission }}$

and,

$$
\text { Equation 32. } Q_{C O_{\text {oxdatain }}}^{\prime \prime}=Q_{\text {Stripping }}^{\prime \prime}+Q_{\text {Reverse }}^{\prime \prime}+\left(\frac{Q_{\text {Stripping }+ \text { Reverse }}^{\prime \prime}}{Q_{\text {Stripping }+ \text { Reverse }}^{\prime}+Q_{\text {Stripping }+ \text { Reverse }}^{\prime \prime}}\right) Q_{\text {Admission }}
$$

The charges from the above equations can then be converted to coverages utilising Equation 3.

The coverages calculated for typical sub-saturated $\mathrm{CO}_{\text {ads }}$ adlayers prepared by partial oxidation

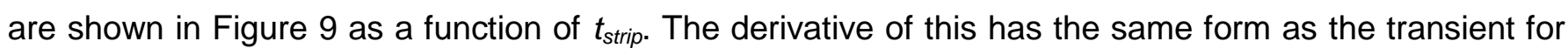
the oxidation of a saturated $\mathrm{CO}_{a d s}$ adlayer shown in Figure 8 (c) as would be expected. Each point represents an individual stripping experiment. The CO coverage quickly approaches 0 within about $1 \mathrm{~s}$, but shows an extended tail. Indeed, the coverages seem to follow a sigmoidal variation with the logarithm of stripping time, Figure 9 inset. Clearly the shape of this curve holds important information about the mechanism for $\mathrm{CO}$ oxidation on our platinum electrode, but we will not analyse this data any more in this paper.

Also displayed in Figure 9 is the total $\mathrm{CO}$ coverage for each stripping experiment, calculated using the sum of Q'co and Q" $\mathrm{co}$. By inspection of the chrono-amperometric transients it is known that the 
oxidation is entirely complete by 3s, therefore the coverage at 3s shown in Figure 9 appears slightly too high, and there appears to be a systematic error which overestimates the $\mathrm{CO}_{\mathrm{ads}}$ coverage at long time. This error seems too high, and therefore there must be some discrepancy in the charges calculated. Such an effect is also seen for the total coverage, for which the points at $2 \mathrm{~s} \& 3 \mathrm{~s}$ appear to be too high. This is thought to be because of errors in the correction for the charge associated with the ORR in the potential step returning to the admission potential, as discussed earlier.

\subsection{The effect of purging time}

As discussed above, for the purposes of calculating coverage it is assumed that no appreciable change in the adlayer will happen over the timescale of the purging (phase (b) in Figure 7), and therefore the charge due to purging will be zero. The purging time is defined as the delay between the admission of the $\mathrm{CO}$ and the oxidation of the $\mathrm{CO}_{\text {ads }}$. During the admission phase of the experiment, upon switching between electrolyte containing dissolved $\mathrm{CO}$ and electrolyte containing dissolved $\mathrm{N}_{2}$, there was no measurable current. In contrast Lopez-Cudero et al [18] showed that on $\mathrm{Pt}(111)$ a maximum coverage of $\theta_{\mathrm{CO}}=0.75$ is achievable in $\mathrm{CO}$ saturated solution, but in $\mathrm{CO}$ free solution a coverage of $\theta_{\mathrm{CO}}=0.68-0.69$ is achievable, and it can take up to 1 hour for the $\mathrm{CO}_{\text {ads }}$ adlayer to equilibrate to the lower coverage via desorption once degassing commences.

Experiments conducted with an increasing time delay between the admission and oxidation phases of the experiment showed no appreciable effect upon the $\mathrm{CO}$ coverage with time present in Figure 10. The rate of loss of $\mathrm{CO}$ from the surface calculated using a linear regression line is $0.32 \%$ Hour $^{-1}$ with an error of $0.94 \%$ Hour $^{-1}$, giving a maximum possible rate of loss of $1.27 \%$ Hour $^{-1}$. This can be used to set an upper limit on $k_{\text {des }}$ (equation 18) of $5.3 \times 10^{-6} \mathrm{~s}^{-1}$, more than 1000 -fold smaller than $k_{\text {ads. }}$ This implies that the $\mathrm{CO}_{\text {ads }}$ is very strongly adsorbed upon the surface and does not appreciably desorb in the absence of $\mathrm{CO}$ in solution at the temperatures of these experiments $\left(25^{\circ} \mathrm{C}\right)$. This also justifies the simplification used in Equation 19 in ignoring the desorption reaction. The very slow rate of CO loss also implies that the heterogeneous reaction between molecular oxygen and adsorbed $\mathrm{CO}$ is very slow under the conditions used within this experiment. This also suggests that the presence of trace amounts of $\mathrm{O}_{2}$ as discussed above, are not reacting directly with the $\mathrm{CO}_{\text {ads }}$ and removing it from the surface.

It is therefore possible to conclude that either it is not possible to achieve a maximum coverage of $\theta_{\mathrm{CO}}=0.75$ in $\mathrm{CO}$ saturated solution for polycrystalline $\mathrm{Pt}$, or that the subsequent desorption process is so fast after switching to $\mathrm{CO}$ free solution that it is not possible to measure it. It appears likely that the former is correct which would be in agreement with Rodes et al. who showed that the formation of compressed structures $\left(\theta_{\mathrm{CO}}=0.75\right)$ is linked to 'perfect' single crystal surfaces, and they are not achievable on polycrystalline surfaces [40]. Either way it is reasonable to assume that once prepared the coverage of the $\mathrm{CO}_{\text {ads }}$ adlayers is stable over the timescales of our experiments. 


\section{Conclusions}

Calculating the coverage of a $\mathrm{CO}_{\text {ads }}$ adlayer using electrochemical measurements can be done accurately and reliably. However, it is not easy, and the charge passed during both admission and oxidation, and either a background or a return to the admission potential must be considered. In addition the presence of $\mathrm{CO}_{\text {ads }}$ may affect any other charge transfer processes that occur, for example the ORR, and even very low concentrations of species such as $\mathrm{O}_{2}$ can seriously affect the results. It is possible to compensate for complications like this, but it must be done very carefully and rigorously. Failure to properly compensate for hydrogen adsorption/desorption, anion adsorption/desorption and double layer effects may lead to an over or underestimation of $\mathrm{CO}_{\text {ads }}$ coverage dependent upon admission potential. At an admission potential of $100 \mathrm{mV}$ this error was calculated to be an underestimation of $34 \%$. This error is related to the admission potential. As the extent of anion adsorption decreases, the error would also decrease. At the potential of zero total charge, the error would be expected to be zero.

The adsorption rate constant for $\mathrm{CO}$ on platinum in sulphuric acid at $25^{\circ} \mathrm{C}$ is calculated to be $0.0086 \mathrm{~cm} \mathrm{~s}^{-1}$. It appears that the presence of $\mathrm{O}_{2}$ at the concentration estimated here of $4.5 \times 10^{-8} \mathrm{~mol} \mathrm{dm}^{-}$

${ }^{3}$ does not react noticeably with $\mathrm{CO}_{\mathrm{ads}}$ in a saturated adlayer, and the $\mathrm{CO}_{\mathrm{ads}}$ adlayers are stable for over $1 \frac{1}{2}$ hours or more.

Calculating the coverage of a partial $\mathrm{CO}_{\mathrm{ads}}$ adlayer prepared via partial oxidation is even more difficult and must be done relative to a known charge for a complete $\mathrm{CO}_{\text {ads }}$ adlayer and a background transient prepared under identical conditions. It is not possible to compensate for any changes in the $\mathrm{CO}_{\mathrm{ads}}$ adlayer between the first and second oxidation steps, although it is likely these occur. Therefore, there are limitations to the accuracy of the coverages calculated for partial adlayers and the errors are likely to be significant at low coverages.

\section{Acknowledgements}

The authors would like to thank Dr. Alan Palmer for his invaluable assistance when using the impinging jet, and Stephen Atkins for his help in building much of the apparatus.

\section{References}

1. A. Lopez-Cudero, A. Cuesta and C. Gutierrez, Journal of Electroanalytical Chemistry, 548, 109-119 (2003).

2. S. B. Brummer and J. I. Ford, The Journal of Physical Chemistry, $\underline{69}, 1355$ (1965).

3. S. Gilman, The Journal of Physical Chemistry, $\underline{68}$, 70-80 (1964).

4. Warner and Schuldiner, Journal of Electrochemical Society, 111, 992 (1964).

5. M. J. Weaver, S. C. Chang, L. W. H. Leung, X. Jiang, M. Rubel, M. Szklarczyk, D. Zurawski and A. Wieckowski, Journal of Electroanalytical Chemistry, 327, 247-260 (1992). 
6. J. M. Feliu, J. M. Orts, A. Femandez-Vega, A. Aldaz and J. Clavilier, Journal of Electroanalytical Chemistry, 296, 191-201 (1990).

7. J. Clavilier, R. Albalat, R. Gomez, J. M. Orts, J. M. Feliu and A. Aldaz, Journal of Electroanalytical Chemistry, 330, 489-497 (1992).

8. C. K. Rhee, J. M. Feliu, E. Herrero, P. Mrozek and A. Wieckowski, Journal of Physical Chemistry, 97, 9730-9735 (1993).

9. $\quad$ E. Herrero, J. M. Feliu and A. Aldaz, Journal of Catalysis, 152, 264-274 (1995).

10. R. Gomez, J. M. Feliu, A. Aldaz and M. J. Weaver, Surface Science, 410, 48-61 (1998).

11. V. Climent, R. Gomez, J. M. Orts, A. Rodes, A. Aldaz and J. M. Feliu, Marcel Dekker, New York, 1999.

12. T. Kobayashi, P. K. Babu, J. H. Chung, E. Oldfield and A. Wieckowski, Journal of Physical Chemistry C, 111, 7078-7083 (2007).

13. Y. X. Chen, M. Heinen, Z. Jusys and R. J. Behm, Journal of Physical Chemistry C, 111, 435-438 (2007).

14. T. J. Schmidt, M. Noeske, H. A. Gasteiger, R. J. Behm, P. Britz, W. Brijoux and H. Bonnemann, Langmuir, 13, 2591-2595 (1997).

15. K. Yamamoto, D. M. Kolb, R. Kotz and G. Lehmpfuhl, Journal of Electroanalytical Chemistry, 96, 233-239 (1979).

16. C. L. Green and A. Kucernak, Journal of Physical Chemistry B, 106, 1036-1047 (2002).

17. M. Bergelin and M. Wasberg, Journal of Electroanalytical Chemistry, $\underline{449}, 181-191$ (1998).

18. A. Lopez-Cudero, A. Cuesta and C. Gutierrez, Journal of Electroanalytical Chemistry, $\underline{579}, 1-12(2005)$.

19. A. Rincon, M. C. Perez, A. Cuesta and C. Gutierrez, Electrochemistry Communications, $\underline{7}, 1027-1032$ (2005).

20. R. lanniello, V. M. Schmidt, U. Stimming, J. Stumper and A. Wallau, Electrochimica Acta, $\underline{39}, 1863-1869$ (1994).

21. C. S. Kim, C. Korzeniewski and W. J. Tornquist, Journal of Chemical Physics, 100, 628630 (1994).

22. H. Kita, S. Ye and K. Sugimura, Journal of Electroanalytical Chemistry, 297, 283-296 (1991).

23. L. Grambow and S. Bruckenstein, Electrochimica Acta, 22, 377-383 (1977).

24. E. P. M. Leiva, E. Santos and T. Iwasita, Journal of Electroanalytical Chemistry, 215, 357-367 (1986).

25. N. Furuya, S. Motoo and K. Kunimatsu, Journal of Electroanalytical Chemistry, 239, 347360 (1988).

26. B. E. Conway, H. Angerstein-Kozlowska and W. B. A. Sharp, Analytical Chemistry, $\underline{45}$, 1331-1336 (1973).

27. C. L. Young, IUPAC Solubility Data Series, Pergamon, 1981.

28. R. M. Q. Mello and E. A. Ticianelli, Electrochimica Acta, 42, 1031-1039 (1997).

29. S. Gottesfeld, I. D. Raistrick and S. Srinivasan, Journal of the Electrochemical Society, 134, 1455-1462 (1987).

30. R. Battino, T. R. Rettich and T. Tominaga, J. Phys. Chem. Ref. Data., 12, 163-178 (1983).

31. D. O. Wipf, A. C. Michael and R. M. Wightman, Journal of Electroanalytical Chemistry, 269, 15-25 (1989).

32. J. L. Melville, B. A. Coles, R. G. Compton, N. Simjee, J. V. Macpherson and P. R. Unwin, Journal of Physical Chemistry B, 107, 379-386 (2003).

33. P. Rieger, Electrochemistry, Chapman \& Hall, New York, 1994. 
34. T. J. Schmidt, H. A. Gasteiger, G. D. Stab, P. M. Urban, D. M. Kolb and R. J. Behm, Journal of the Electrochemical Society, 145, 2354-2358 (1998).

35. M. Bergelin, J. M. Feliu and M. Wasberg, Electrochimica Acta, 44, 1069-1075 (1998).

36. P. Stonehart, Electrochimica Acta, 12, 1185-1198 (1967).

37. H. A. Gasteiger, N. M. Markovic and P. N. Ross, Journal of Physical Chemistry, 99, 8945-8949 (1995).

38. X. L. J.J. Baschuk, International Journal of Energy Research, 27, 1095-1116 (2003).

39. N. P. Lebedeva, M. T. M. Koper, J. M. Feliu and R. A. van Santen, Journal of Electroanalytical Chemistry, 524, 242-251 (2002).

40. A. Rodes, R. Gomez, J. M. Feliu and M. J. Weaver, Langmuir, 16, 811-816 (2000). 


\section{Figure Captions}

Figure 1. Cartoon depicting the impinging jet flow cell apparatus, (a). The flow rate was approximately $6 \times 10^{-3} \mathrm{~cm}^{-3} \mathrm{~s}^{-1}$, the capillary tube internal diameter was $0.53 \mathrm{~mm}$, the electrode diameter $125 \mu \mathrm{m}$, and the distance from the capillary tube to the electrode approximately $2 \mathrm{~mm}$. (b) shows a close-up of the working electrode. The counter and reference electrodes are both in the bulk solution and are in electrochemical contact with the working electrode through the meniscus, flow rate through the meniscus is faster than diffusion removing reaction products and preventing contamination of the electrode surface from the bulk.

Figure 2. Diffusion limiting current (calculated using geometric surface area) for hydrogen oxidation at a potential of $100 \mathrm{mV}$ on a $25 \mu \mathrm{m}$ diameter polycrystalline $\mathrm{Pt}$ electrode $(3000 \mu \mathrm{m}$ diameter glass sheath surrounding electrode) in a jet of solution containing $\mathrm{H}_{2}$ saturated $0.5 \mathrm{~mol} \mathrm{dm}^{-3} \mathrm{H}_{2} \mathrm{SO}_{4}(\square)$. The calculated boundary layer thickness as the electrode is translated from immediately above the centre of the jet $(530 \mu \mathrm{m}$ internal diameter) radially is shown (dashed line). The zero point on the horizontal scale corresponds to the electrode being positioned coaxially with the jet (i.e. the same configuration as shown in Figure 1(b)).

Figure 3. Cartoon showing the potential steps and current transients associated with the preparation and complete oxidation of a $\mathrm{CO}_{\mathrm{ads}}$ adlayer, and for the control case when no $\mathrm{CO}$ is adsorbed on the surface. The only difference between the two experiments is that during the admission phase (b) $\mathrm{CO}$ is present in the solution for the first case, and not for the control experiment.

Figure 4. Chronoamperometric transients at a potential of $100 \mathrm{mV}^{2} \mathrm{~N}_{2}$-saturated $0.5 \mathrm{~mol} \mathrm{dm}^{-3}$ $\mathrm{H}_{2} \mathrm{SO}_{4}$ for the admission of a CO-saturated $0.5 \mathrm{~mol} \mathrm{dm}^{-3} \mathrm{H}_{2} \mathrm{SO}_{4}$ for 60 s after a delay of roughly $35 \mathrm{~s}$ (black line), and a control where no CO-saturated solution is admitted to the surface (grey line), (a). Subtraction of the control chrono-amperometric transient from the chrono-amperometric transient where $\mathrm{CO}$ is admitted to the surface, (b). Baseline for integration of this transient is also shown (…...).

Figure 5. Chrono-amperometric transients at a potential of $700 \mathrm{mV}$ in $\mathrm{N}_{2}$-saturated $0.5 \mathrm{~mol} \mathrm{dm}^{-3}$ $\mathrm{H}_{2} \mathrm{SO}_{4}$ for the oxidation of a $\mathrm{CO}_{\text {ads }}$ adlayer prepared by admission of CO-saturated $0.5 \mathrm{~mol} \mathrm{dm}^{-3}$ $\mathrm{H}_{2} \mathrm{SO}_{4}$ for a period of $60 \mathrm{~s}$ at $100 \mathrm{mV}$ (black line), and a control for a surface with no CO present but which has undergone the same potential regime (grey line) (a). Followed by subtraction of the control transient from the $\mathrm{CO}_{\mathrm{ads}}$ oxidation transient (b). And finally, the integration of the current passed after subtraction of the control transient (c). 
Figure 6. $\mathrm{CO}$ coverage for a polycrystalline $\mathrm{Pt}$ electrode in $\mathrm{N}_{2}$-saturated $0.5 \mathrm{~mol} \mathrm{dm}^{-3} \mathrm{H}_{2} \mathrm{SO}_{4}$ of $\mathrm{CO}_{\text {ads }}$ adlayers produced by exposing the electrode to bursts of $\mathrm{CO}$-saturated $0.5 \mathrm{~mol} \mathrm{dm}^{-3} \mathrm{H}_{2} \mathrm{SO}_{4}$ for various lengths of time. Admission potentials of $67 \mathrm{mV}$.

Figure 7. Cartoon showing the potential steps and current transients associated with the preparation of a partial $\mathrm{CO}_{\text {ads }}$ adlayer by partially oxidising a saturated adlayer for a period of $t_{\text {strip }}$. This then followed by a complete oxidation of the remaining layer.

Figure 8. Chrono-amperometric transients at a potential of $100 \mathrm{mV}$ in $\mathrm{N}_{2}$-saturated $0.5 \mathrm{~mol} \mathrm{dm}^{-3}$ $\mathrm{H}_{2} \mathrm{SO}_{4}$ for the admission of CO-saturated $0.5 \mathrm{~mol} \mathrm{dm}^{-3} \mathrm{H}_{2} \mathrm{SO}_{4}$ for a period of $10 \mathrm{~s}(\mathrm{a})$, compared to the background transient (b). Followed by the transients in $\mathrm{N}_{2}$-saturated $0.5 \mathrm{~mol} \mathrm{dm}^{-3} \mathrm{H}_{2} \mathrm{SO}_{4}$ for the oxidation of the $\mathrm{CO}_{\mathrm{ads}}$ adlayer at $700 \mathrm{mV}$ for $0.1 \mathrm{~s}(---)$ and $3 \mathrm{~s}(-)$ (c), and the return step to $100 \mathrm{mV}$ (d). And finally, the transients in $\mathrm{N}_{2}$-saturated $0.5 \mathrm{~mol} \mathrm{dm}^{-3} \mathrm{H}_{2} \mathrm{SO}_{4}$ for the oxidation of the remaining $\mathrm{CO}_{\mathrm{ads}}$ at $800 \mathrm{mV}$ for $10 \mathrm{~s}(\mathrm{e})$, and the return step to $100 \mathrm{mV}(\mathrm{f})$.

Figure 9. $\quad \mathrm{CO}_{\mathrm{ads}}$ coverages remaining after partial oxidation for $\mathrm{CO}_{\mathrm{ads}}$ adlayers prepared by admission of $\mathrm{CO}$ from CO-saturated $0.5 \mathrm{~mol} \mathrm{dm}^{-3} \mathrm{H}_{2} \mathrm{SO}_{4}$ at a potential of $100 \mathrm{mV}$ for $10 \mathrm{~s}$, followed by partial oxidation in $\mathrm{N}_{2}$-saturated $0.5 \mathrm{~mol} \mathrm{dm}^{-3} \mathrm{H}_{2} \mathrm{SO}_{4}$ at a potential of $800 \mathrm{mV}$ for lengths of time between $0.005 \mathrm{~s}$ and $3 \mathrm{~s}, \square$. Following the formation of the partial $\mathrm{CO}$ adlayer, the remaining $\mathrm{CO}$ was completely oxidised at a potential of $800 \mathrm{mV}$ for $10 \mathrm{~s}$. The coverage was calculated using the corrected oxidation charges, Equation 31\&32. The total $\mathrm{CO}$ coverage obtained from $Q_{C O_{\text {oxidation }}}^{\prime}+Q_{C O_{\text {oxidation }}}^{\prime \prime}$ is also plotted, (O). Inset shows the same data represented with a semilogarithmic plot.

Figure 10. $\mathrm{CO}_{\mathrm{ads}}$ coverages after partial oxidation for $\mathrm{CO}_{\mathrm{ads}}$ adlayers prepared by admission of $\mathrm{CO}$ from CO-saturated $0.5 \mathrm{~mol} \mathrm{dm}^{-3} \mathrm{H}_{2} \mathrm{SO}_{4}$ at a potential of $100 \mathrm{mV}$ for $10 \mathrm{~s}$, followed by partial oxidation in $\mathrm{N}_{2}$-saturated $0.5 \mathrm{~mol} \mathrm{dm}^{-3} \mathrm{H}_{2} \mathrm{SO}_{4}$ at a $\mathrm{CO}_{\text {ads }}$ coverages remaining after saturated $\mathrm{CO}$ adlayers (prepared by admission from CO-saturated $0.5 \mathrm{~mol} \mathrm{dm}^{-3} \mathrm{H}_{2} \mathrm{SO}_{4}$ at a potential of $100 \mathrm{mV}$ for $60 \mathrm{~s}$ ) were held at potentials of $100 \mathrm{mV}$ in $\mathrm{N}_{2}$-saturated $0.5 \mathrm{~mol} \mathrm{dm}{ }^{-3} \mathrm{H}_{2} \mathrm{SO}_{4}$ for different lengths of time. 


\section{Figures}

Figure 1

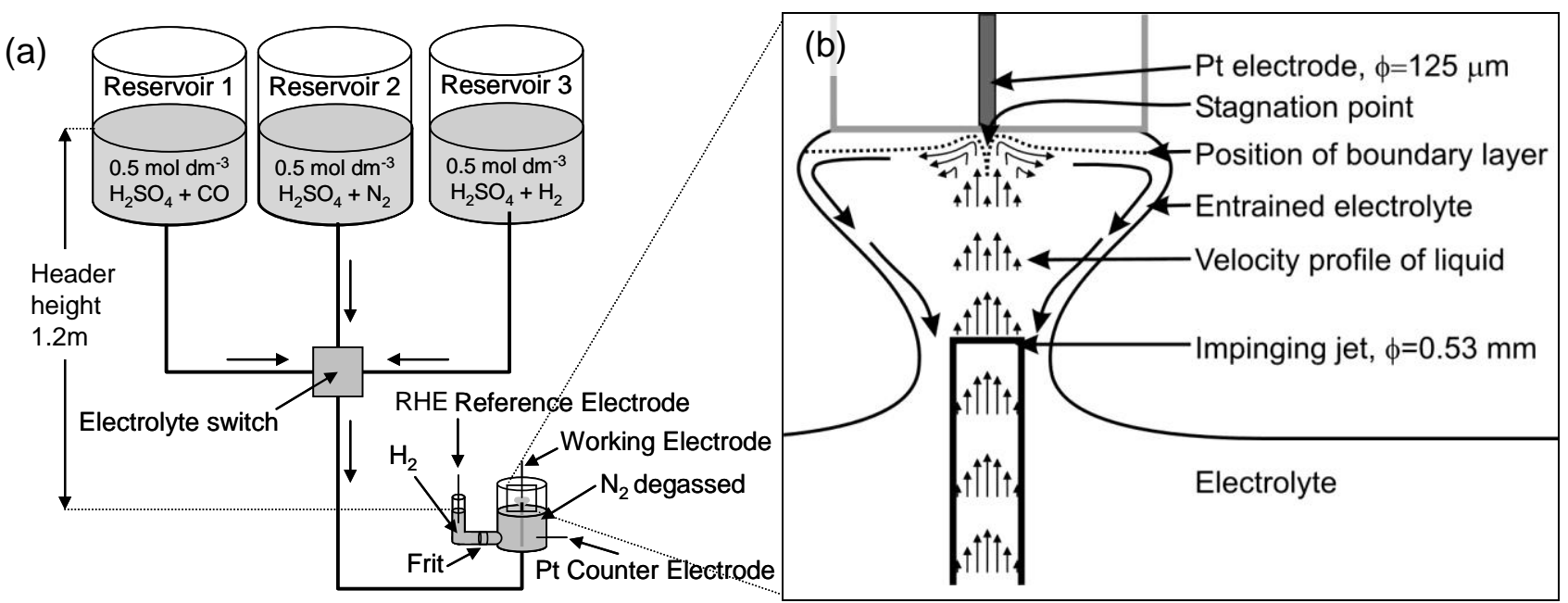

Figure 2

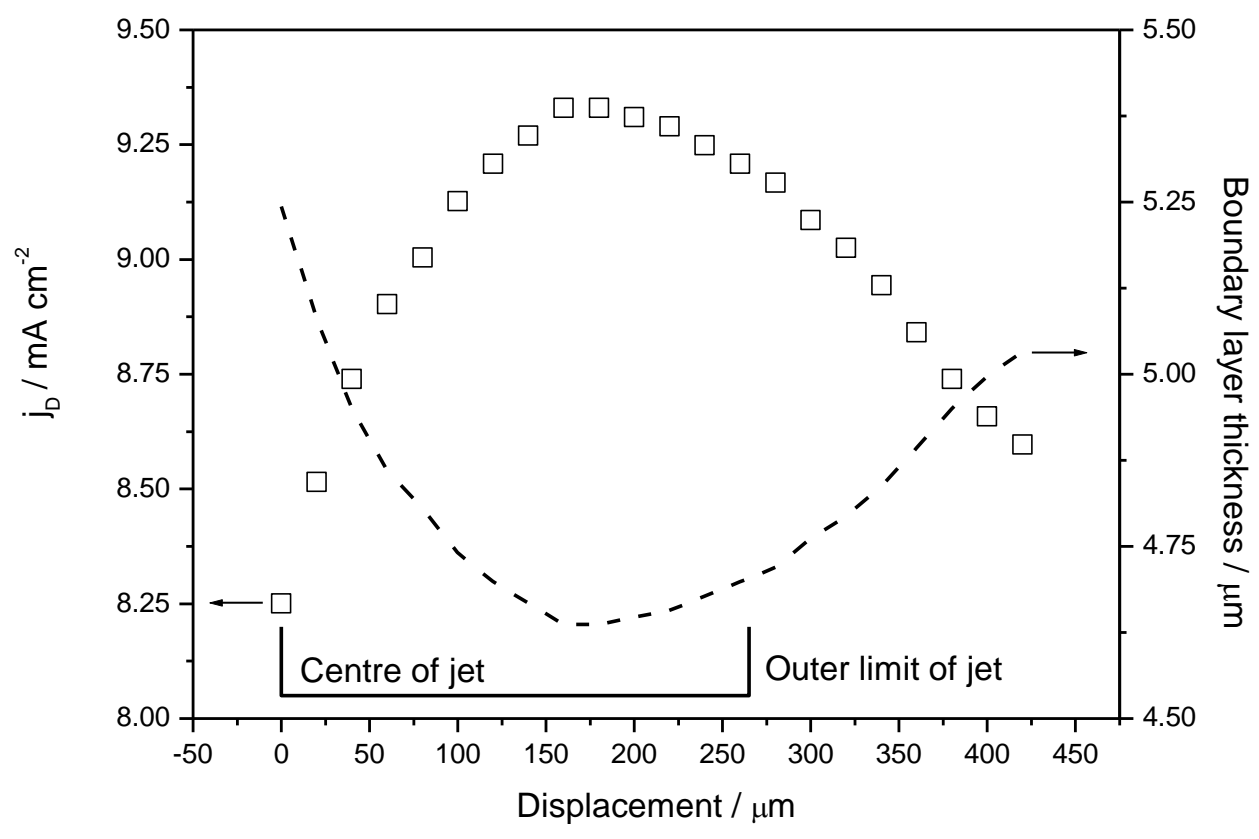


Figure 3

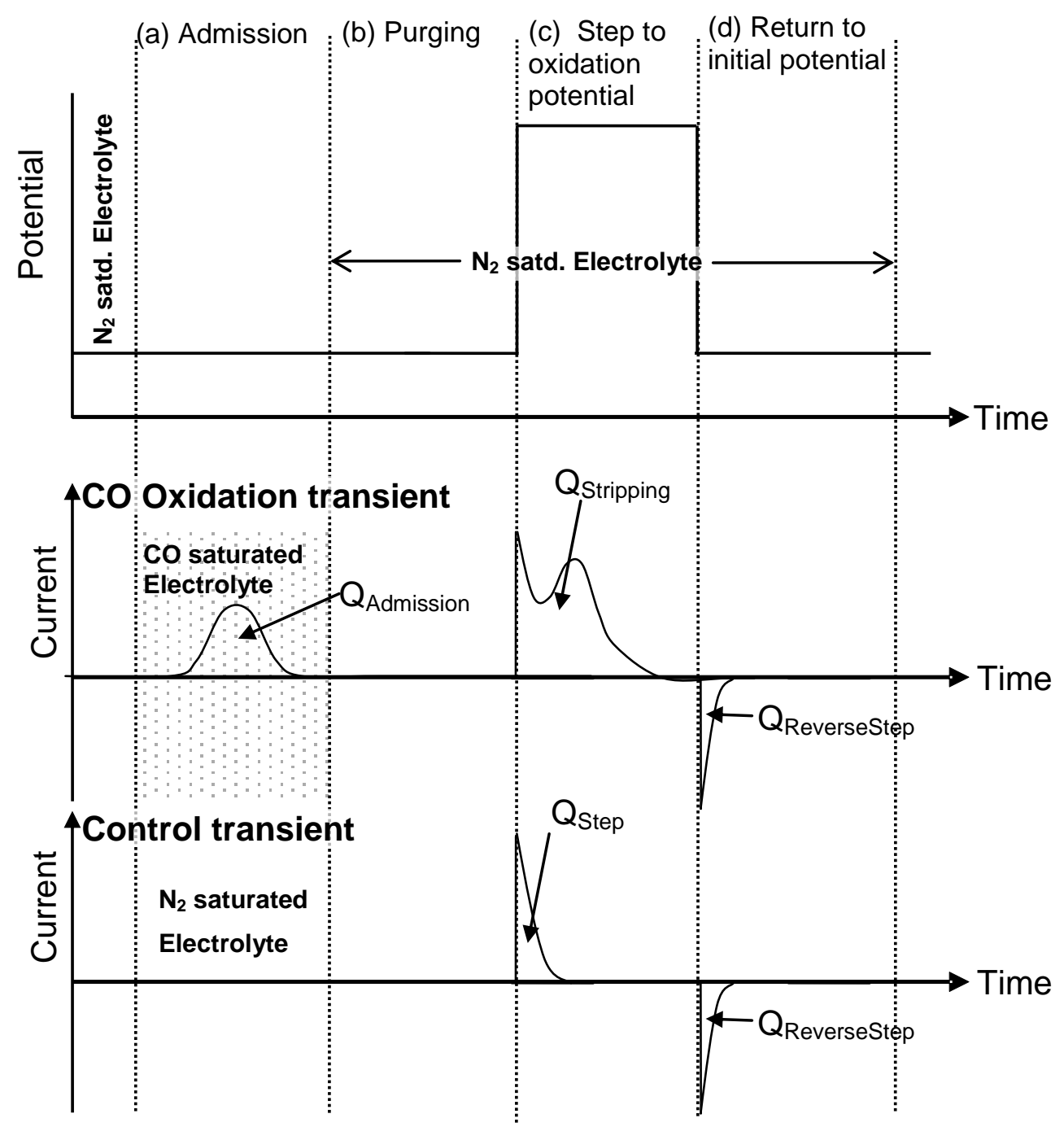


Figure 4

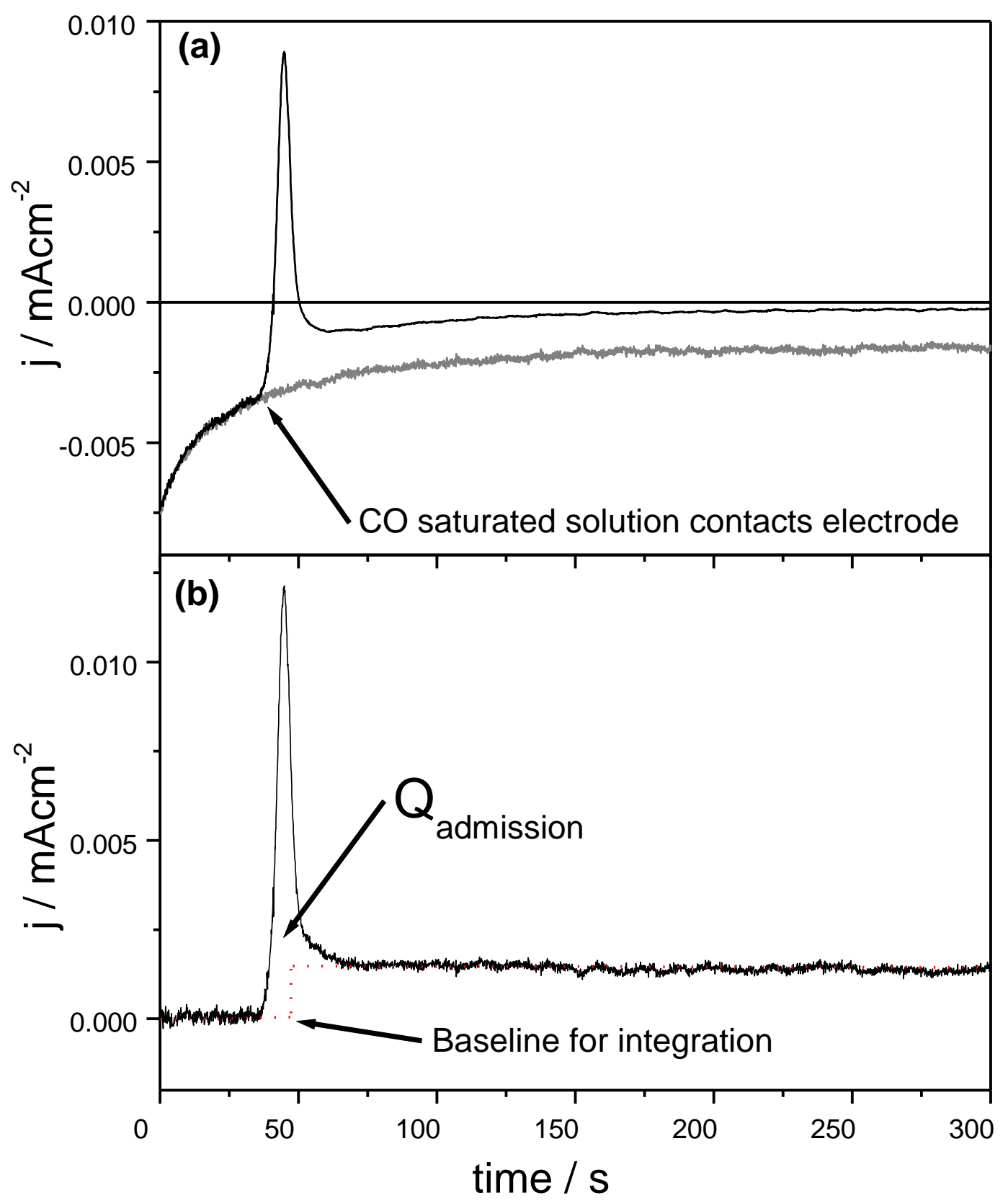


Figure 5
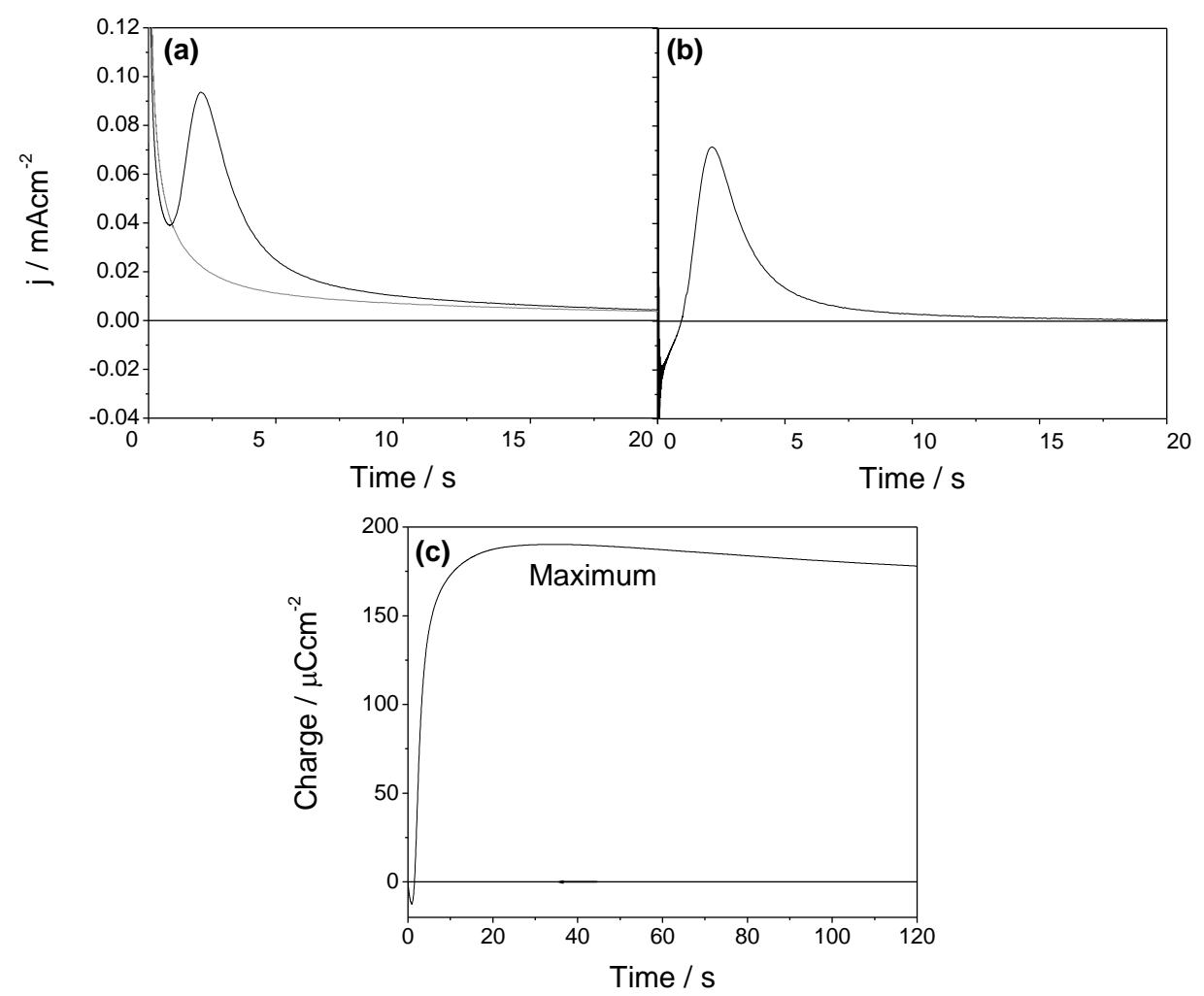

Figure 6

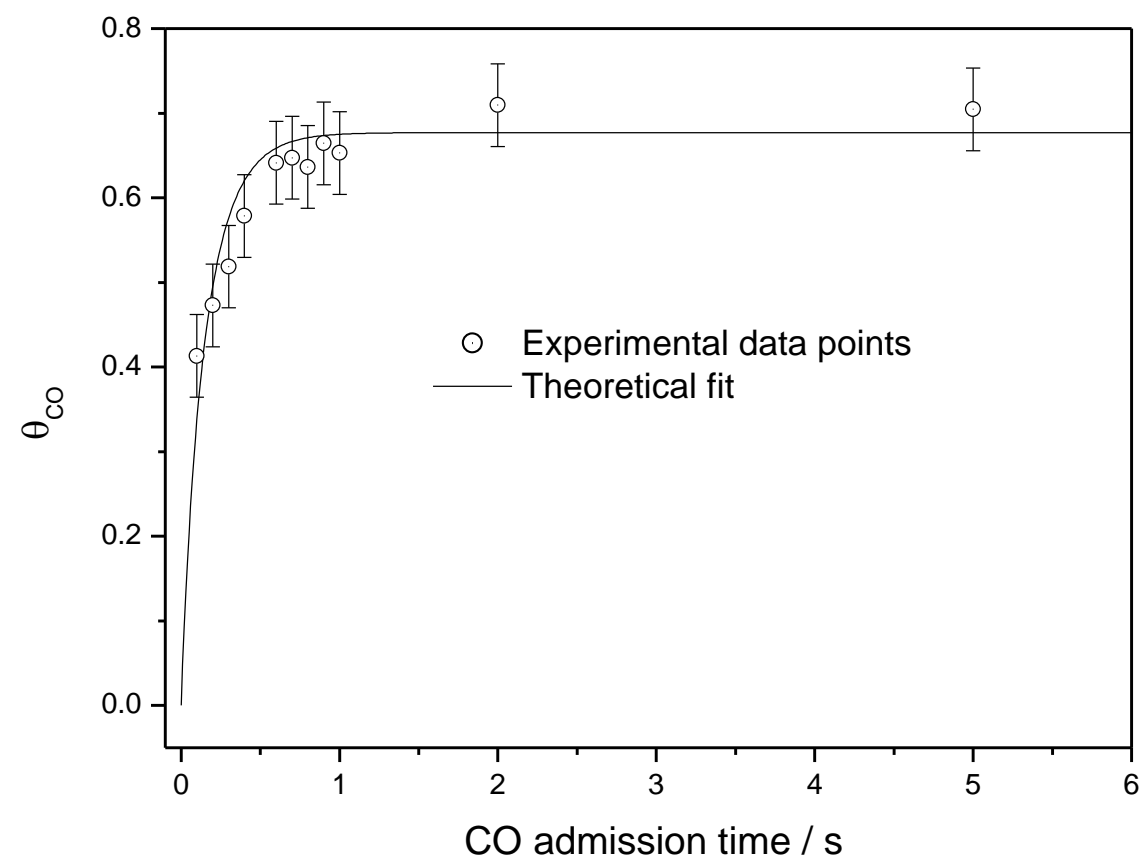


Figure 7

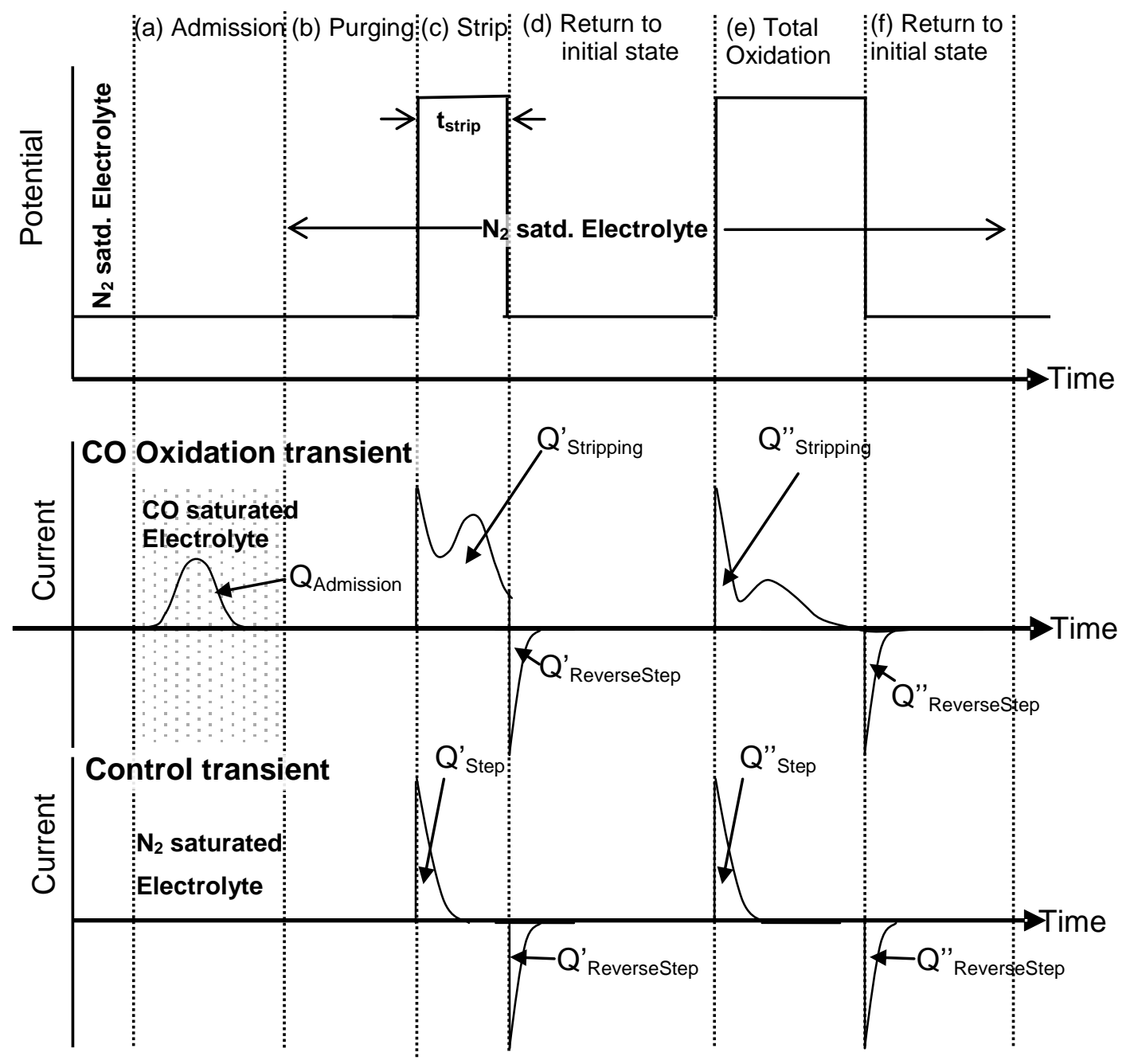


Figure 8
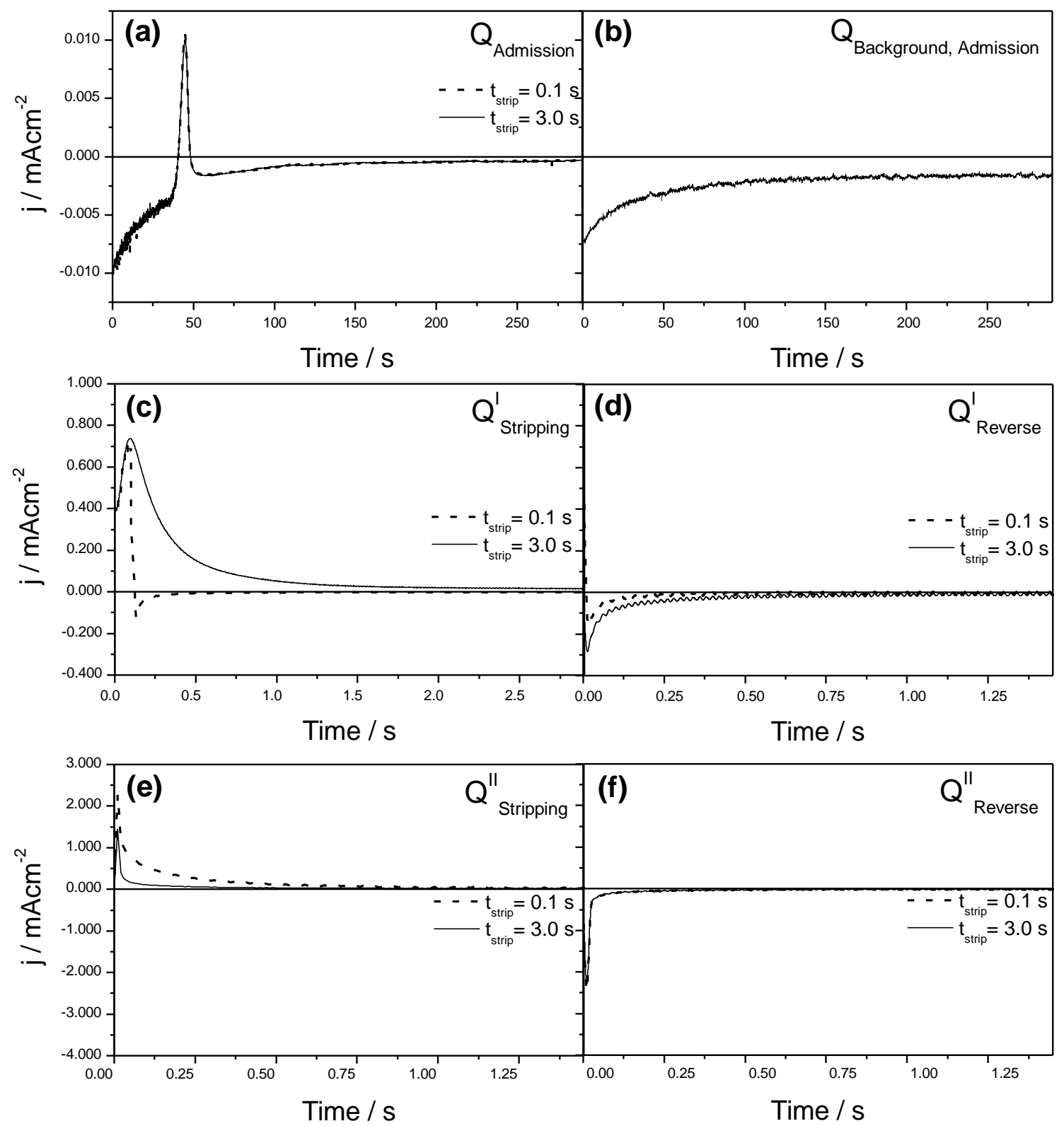
Figure 9

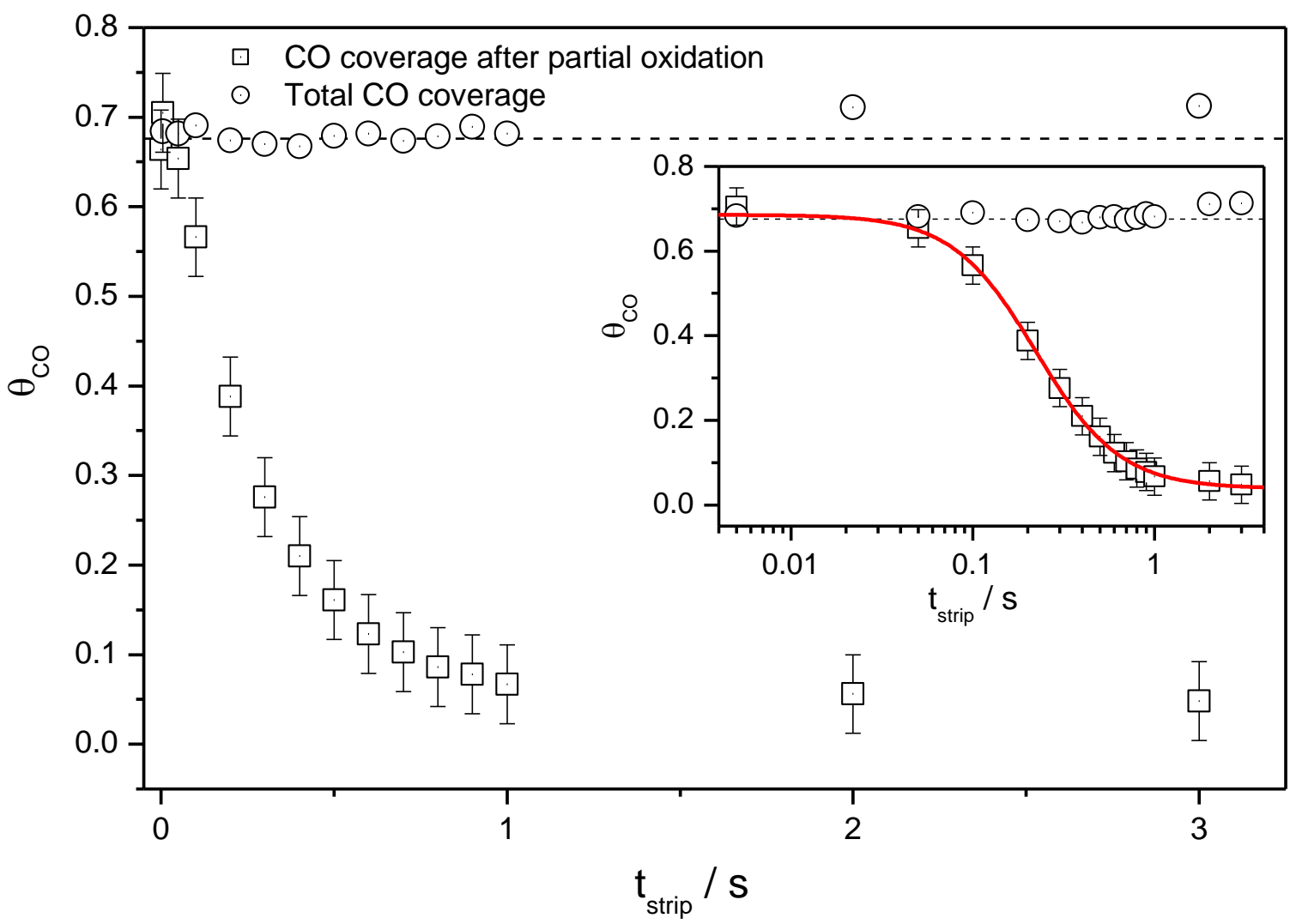

Figure 10

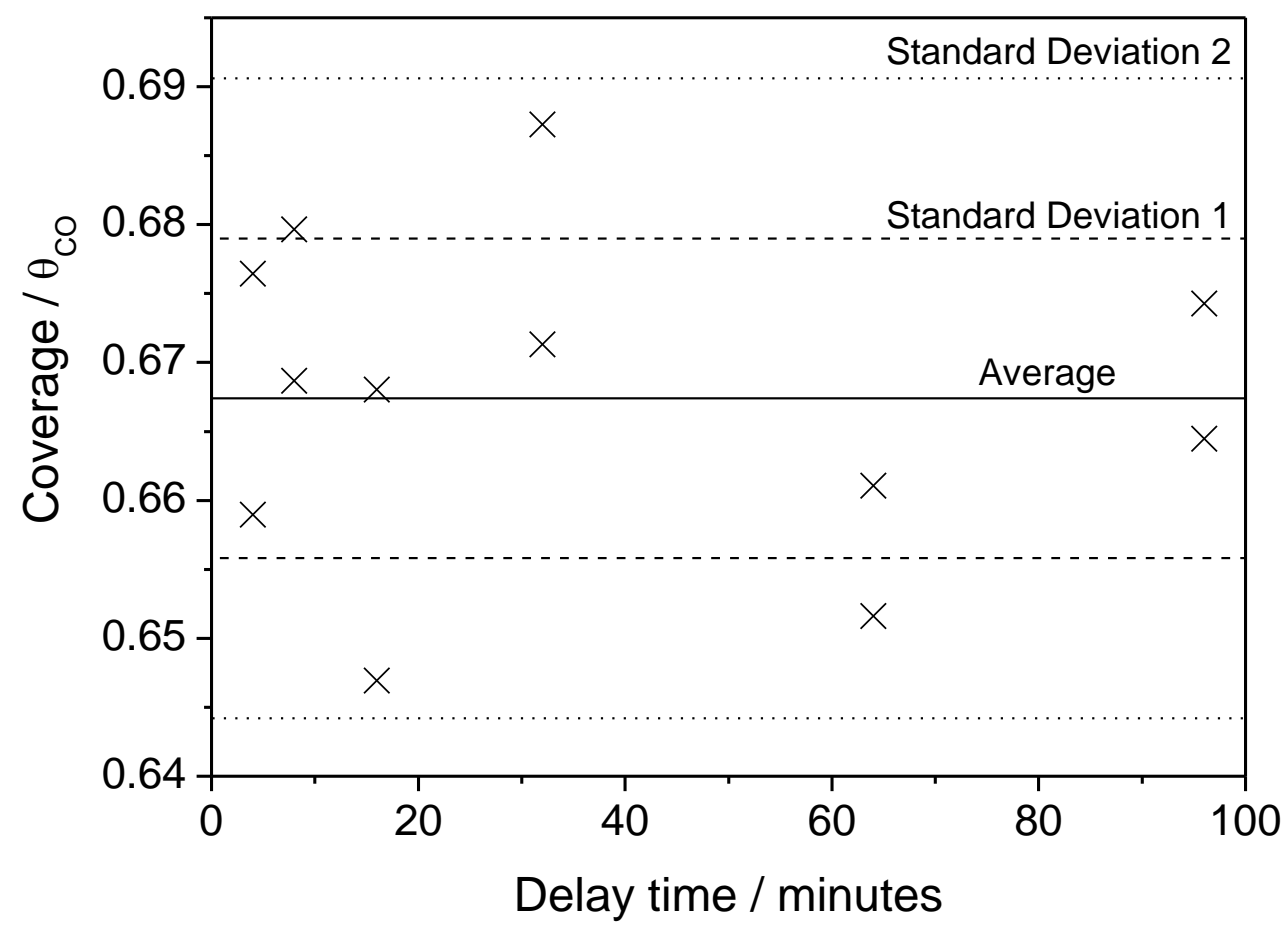

Page 30 of 31 
Table 1 Charge consumed by each of the two major steps associated with CO oxidation - admission and stripping. The errors associated with calculating these charges and the resulting CO coverage. Errors are calculated from the statistical analysis of five experiments.

\begin{tabular}{l|l|l|l} 
& \multicolumn{2}{l}{ Charges / nC } & \\
& Mean & Standard Deviation (SD) & Error (SD/Mean) \\
\hline$Q_{\text {Admission }}-Q_{\text {BackgroundAdmission }}$ & 37.3 & 1.146 & $3.07 \%$ \\
\hline$Q_{\text {Stripping }}-Q_{\text {BackgroundStripping }}$ & & & $1.51 \%$ \\
\hline$Q_{C O_{\text {oxidation }}}$ & 71.2 & 1.689 & $0.82 \%$ \\
\hline Coverage $\left(\theta_{\mathrm{CO}}\right)$ & 108.5 & 1.26 & $1.17 \%$
\end{tabular}

